\title{
Technical Review of Dual Inverter Topologies for More Electric Aircraft Applications
}

\author{
Zhen Huang, Tao Yang, Senior Member, IEEE, Paolo Giangrande, Senior Member, IEEE, Michael Galea, Senior \\ Member, IEEE, and Patrick Wheeler, Fellow, IEEE
}

\begin{abstract}
Electric drives are an essential part of more electric aircraft (MEA) applications with ever-growing demands for high power density, high performance, and high fault-tolerant capability. High-speed motor drives can fulfil those needs, but their speeds are subject to the relatively low DC-link voltage adopted by MEA. The power inverters are thus expected to efficiently and effectively manage that limited voltage. A recently popular topology is represented by the dual inverters. They are featured by inherited fault tolerance, a high DC-link voltage utilization and an excellent output power profile. This paper aims to present a comprehensive review of different structures based on the dual inverter. To meet the stringent requirements of MEA applications, three performance aspects, including the voltage utilization, the inverter output quality and the faulttolerant capability, are selected. Based on the chosen performance metrics, the key features of adopting dual inverter topologies against other converter selections are explicitly demonstrated. Finally, a practical guideline for choosing suitable dual inverters for different MEA applications is provided.
\end{abstract}

Index Terms-Dual inverter, floating bridge, multilevel inverters, space vector modulation, voltage regulation

\section{BACKGROUND}

In civilian aircraft, the gas turbines provide the power primarily for the propulsion thrust and the secondary power required for all the onboard systems [1]-[3]. To enhance the secondary power system controllability and overall performance, more electric aircraft (MEA) initiative has been developed, progressively replacing the pneumatic, hydraulic and mechanical sources with their electric counterparts [4], [5].

Electrical drives enable the adoption of MEA concept facilitating cost-effective and efficient renewable energy generation and conversion [2], [6]. For a representative MEA onboard system shown in Fig. 1 [7], electrical drives can be found in the energy generation system, including starter-generators (SG)/generators [1], [8]-[10], and energy consumption loads covering wing ice protection system (WIPS), flight control

Manuscript received Month xx, 2xxx; revised Month xx, xxxx; accepted Month X, Xxxx. This work was supported by the Clean Sky 2 Joint Undertaking under the European Union's Horizon 2020 research and innovation programme under grant agreement number 807081. (Corresponding author: Tao Yang.)

Z. Huang, T. Yao, P. W. Wheeler, M. Galea and P. Giangrande are with the Power Electronics Machines and Control Group, Department of Electrical and Electronics Engineering, University of Nottingham, Nottingham, NG7 2RD, UK. (e-mails: zhen.huang@ @ottingham.ac.uk, tao.yang@ nottingham.ac.uk, pat.wheeler@nottingham.ac.uk, paolo.giangrande@nottingham.ac.uk).

M. Galea is also with the University of Nottingham Ningbo China, Ningbo 315100, China.

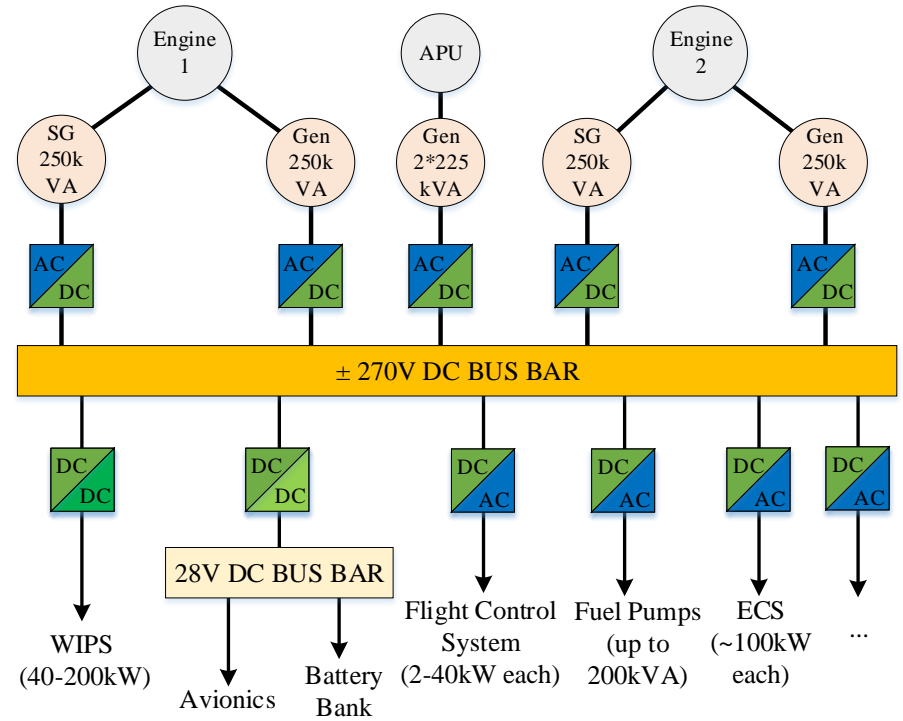

Fig. 1: Onboard electrical system architecture in MEA. (APU: auxiliary power unit)

system, fuel pumps, environmental control system (ECS), etc. [3], [10]. The estimated power levels of those electric systems for a medium/large MEA are indicated in Fig. 1. Compared to using non-electric systems, the ones with electric power can achieve gains in the overall efficiency, weight/cost saving while maintaining reliability [10]-[13].

However, today there is an ever-growing need for higher performance and more efficient systems. Especially from a transport industry perspective, today the industry is facing immense challenges related to emissions and efficiency. Higher power densities, coupled with excellent efficiency are fast becoming the standard requirement for applications in the MEA. A common approach to meet the requirement of high power density is by looking at higher speed drives [14], [15].

For a motor drive, its wide-speed operation is subject to the supply voltage from the power converters [16]. Entering the field-weakening region is not favourable as it may result in potentially higher losses [17]. As the motor's back electromotive force (EMF) grows linearly with speed, a sufficiently high output voltage from inverters is essential [14], [18]. However, the reality is that for MEA applications, the most common DC-link feeding the power inverters value is $270 \mathrm{~V}$ or $540 \mathrm{~V}$ as seen in Fig. 1. A DC-DC boost converter is typically adopted, but extra power electronics simply lower the system reliability [19]-[21]. Another concept was to adopt a variable 
voltage DC bus where WIPS has been taken as the case study in [22]. However, regardless of different DC-link voltages, greater utilization of the power inverters is highly expected [23]. A larger speed without field weakening could allow the machine to minimize its weight and volume considerately, which can be beneficial for MEA applications [24], [25].

On the other side, it is very important to note that for aerospace applications, simply having better power densities is not enough. Regardless of how pushed the design is in terms of power density, the electrical drive still needs to respect the fault-tolerant capabilities that are set for such safety-critical applications [6] [26]. Driven by the motivations of enhancing DC-link voltage utilization, the power quality as well as the fault-tolerant capability, new inverter topologies as well as adapting advanced modulation schemes are being intensively investigated [27].

Multilevel inverters are being recognized as one of the most promising solutions for MEA applications. Their reduced $\mathrm{d} v / \mathrm{d} t$, better power quality and higher efficiency are perceived to give a significant advantage over traditional two-level inverters [28]. Cascaded H-bridge inverters (CHI), flying-capacitor inverters (FCI) and diode-clamped inverters (DCI) are the three most recognized multilevel inverters [13].

A recent very popular configuration is represented by the dual inverter topology. It employs two standard two-/multilevel converters connecting to either side of an open-end winding (OeW) machine [29], [30]. This configuration offers excellent redundancy [8] and fault-tolerant ability [21] using a reduced device count [31] in comparison to other multilevel inverters configurations. For a given amount of switching devices, the number of isolated supplies, capacitors with voltage regulation needs, and diodes needed by a dual inverter are less than the number required for a CHI, FCI, and DCI, respectively [24], [31]. From the above, it can be concluded that the dual inverter has great control flexibility from its abundant switching states within a relatively simple structure. Therefore, this topology now is very attractive for aerospace applications.

Compared to other multilevel inverters, dual inverters are featured by three design freedom that may further enhance the converter performance. The first one is for the power supplies arrangements. There are three choices, namely the dual inverter with two isolated voltage sources, with a common DC-link and with a floating capacitor (FC) [32].

Secondly, two modulation schemes, namely the coupled method and the decoupled modulation, can be alternatively applied for dual inverters. The previous one modulates the reference vector for a whole dual inverter, while the latter resolvers the reference vector into two vectors, each representing one inverter [33]. Substantially, the coupled modulation perceives the dual inverter as a whole converter for modulation, whereas the decouple one considers it as two separate systems.

The last design freedom of a dual inverter is the assignment of the voltage ratio between two inverters. It is reported the dual inverters can enhance their performance by identifying appropriate voltage ratios. The improvement consists of improving the converter output quality by increasing the number of output voltage levels [25], [31], [33]-[38] and boosting the

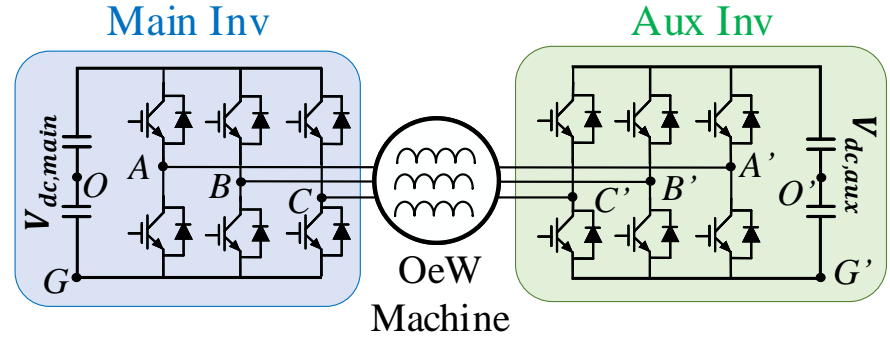

Fig. 2: Schematic of the motor drive with a dual inverter.

DC-link voltage utilization [16], [25], [39]-[42].

However, similar to a CHI, an FCI, or a DCI, the capacitors' voltages of the dual inverters also have to be properly controlled. Otherwise, the voltage steps that are clamped by capacitor voltages would be altered, and then undesirable harmonic distortion will be induced in the inverter output, deteriorating its quality. To fully exploit the potentials of dual inverters with exclusive design freedom, the capacitor voltage regulation is the main challenge [25].

In this paper, the operation principle of dual inverters will be briefly introduced in Section II. This is followed by reviewing three exclusive design freedom featured by dual inverters, the configurations in Section III, modulation schemes in Section IV, and voltage ratio assignments in Section $\mathrm{V}$ that may optimize their performance. With those design potentials, Section VI summarizes the addressed voltage regulation schemes in literature. The performance evaluation of dual inverter topologies is comprehensively assessed in Section VII. Based on that, Section VIII provides recommendations of suitable dual inverter configurations for MEA applications, and the conclusions are drawn in Section IX.

\section{DUAl InVERTER OPERATION PRINCIPLE}

Considering the motor drive in Fig. 2, one can observe the dual inverter configuration, where the left inverter in blue colour is called the Main-Inv and the right-hand side one in green colour is denoted as the Aux-Inv. The OeW machine is connected between the AC outputs of the Main-Inv (main inverter) and Aux-Inv (auxiliary inverter), as shown in Fig. 2. Fig. 2 shows the supplied voltages of the Main-Inv and Aux-Inv are assigned to $V_{d c, \text { main }}$ and $V_{d c, a u x}$, respectively.

Considering the loops AA'O'O, BB'O'O, CC'O'O in Fig. 2 , the three-phase voltages $V_{A A^{\prime}}, V_{B B^{\prime}}$ and $V_{C C^{\prime}}$ can be expressed by (1) according to Kirchhoffs Voltage Law (KVL),

$$
\left\{\begin{array}{l}
V_{A A^{\prime}}=V_{A O}-V_{A^{\prime} O^{\prime}}+V_{O O^{\prime}} \\
V_{B B^{\prime}}=V_{B O}-V_{B^{\prime} O^{\prime}}+V_{O O^{\prime}} \\
V_{C C^{\prime}}=V_{C O}-V_{C^{\prime} O^{\prime}}+V_{O O^{\prime}}
\end{array}\right.
$$

where $V_{A O}, V_{B O}, V_{C O}$ and $V_{A^{\prime} O^{\prime}}, V_{B^{\prime} O^{\prime}}, V_{C^{\prime} O^{\prime}}$ are the three-phase pole voltages for the Main-Inv and Aux-Inv, respectively.

Assuming the three-phase loads are symmetrical, then as stated in (2), the sum of load phase voltages should be zero. Thus, $V_{O O^{\prime}}$ can be derived by adding three equations in (1), as shown in (3). 


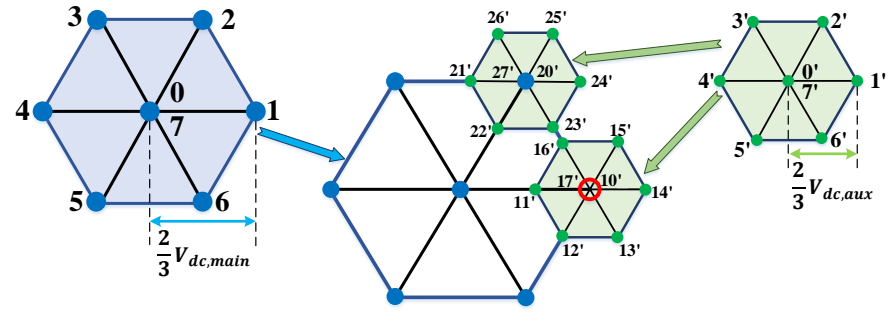

Fig. 3: Space vector diagram by a dual inverter.

$$
\begin{gathered}
V_{A A^{\prime}}+V_{B B^{\prime}}+V_{C C^{\prime}}=0 \\
V_{O O^{\prime}}=\frac{V_{A^{\prime} O^{\prime}}+V_{B^{\prime} O^{\prime}}+V_{C^{\prime} O^{\prime}}}{3}-\frac{V_{A O}+V_{B O}+V_{C O}}{3}
\end{gathered}
$$

Substituting (3) into (1), then the phase voltage expression can be updated to (4),

$$
\left\{\begin{array}{l}
V_{A A^{\prime}}=\left(\frac{2}{3} V_{A O}-\frac{1}{3} V_{B O}-\frac{1}{3} V_{C O}\right)-\left(\frac{2}{3} V_{A^{\prime} O^{\prime}}-\right. \\
\left.\frac{1}{3} V_{B^{\prime} O^{\prime}}-\frac{1}{3} V_{C^{\prime} O^{\prime}}\right) \\
V_{B B^{\prime}}=\left(\frac{2}{3} V_{B O}-\frac{1}{3} V_{C O}-\frac{1}{3} V_{A O}\right)-\left(\frac{2}{3} V_{B^{\prime} O^{\prime}}-\right. \\
\left.\frac{1}{3} V_{C^{\prime} O^{\prime}}-\frac{1}{3} V_{A^{\prime} O^{\prime}}\right) \\
V_{C C^{\prime}}=\left(\frac{2}{3} V_{C O}-\frac{1}{3} V_{A O}-\frac{1}{3} V_{B O}\right)-\left(\frac{2}{3} V_{C^{\prime} O^{\prime}-}\right. \\
\left.\frac{1}{3} V_{A^{\prime} O^{\prime}}-\frac{1}{3} V_{B^{\prime} O^{\prime}}\right)
\end{array}\right.
$$

From (4), it can be found that the phase voltage applied from a dual inverter on the OeW machine in Fig. 2 is the phase voltage difference produced by the two inverters (i.e. the MainInv and the Aux-Inv). Based on that, the resultant space vector diagram of a dual inverter can be showed in Fig. 3, where the set of space vector hexagons due to the Aux-Inv 'orbiting' the space vector hexagon of the Main-Inv.

Generally, the voltage applied to the machine is represented by the switching states of both inverters. For instance, the switching state 15' indicates 1 (100) for the Main-Inv and 5' (001) for the Aux-Inv. The three numbers within the bracket, such as (100) and (001), indicate the states of the top switches for each leg in Fig. 2. In Fig. 3, each dot represents one switching vector, and it can be expressed by several switching states. These are known as redundant states. For example, the vector denoted in red circle in Fig. 3 can be represented by either $10^{\prime}$ or $17^{\prime}$. For a standard two-level three-phase converter, there are eight switching states to form seven vectors in the plane. Since a dual inverter employs two two-level inverters, it possesses $8^{2}=64$ switching states.

In Fig. 3, the area of space vector diagrams for the MainInv and Aux-Inv is defined by their supplied voltages $V_{d c, \text { main }}$ and $V_{d c, a u x}$, respectively. From Fig. 3, it can be observed that the space vector diagram of a dual inverter is dependent on the voltage ratio between $V_{d c, \text { main }}$ and $V_{d c, a u x}$. A comprehensive study on this ratio will be reviewed in Section V.

\section{Dual Inverter Design Freedom (1): CONFIGURATIONS}

\section{A. Type I}

As shown in Fig. 4, there are three different arrangements for power sources in a dual inverter. They can be either two

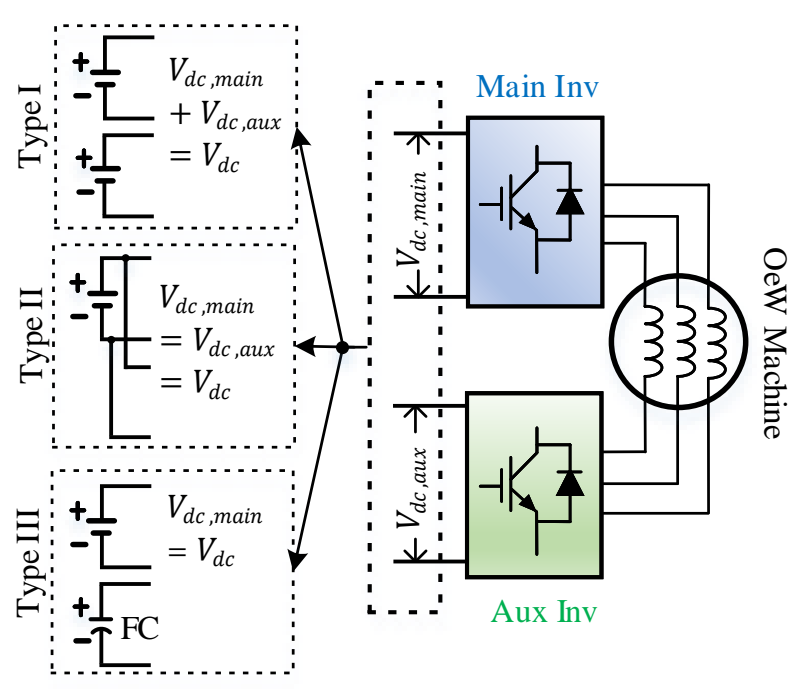

Fig. 4: Three configurations of dual inverter topology.

TABLE I: Three dual inverter configurations and their applications

\begin{tabular}{cccc}
\hline & \multicolumn{3}{c}{ Dual Inverter Configurations } \\
& Type I & Type II & Type III \\
\hline $\begin{array}{c}\text { DC-link Voltage } \\
\text { Utilization } \boldsymbol{k}\end{array}$ & $\leq 1$ [43], [44] & $1-2[45]$ & $>1$ [24] \\
\hline $\begin{array}{c}\text { Number of } \\
\text { Output Levels }\end{array}$ & $\geq 3[31]$ & $2[46]$ & $\geq 3[31]$ \\
\hline MEA & & $\begin{array}{c}\text { Starter-generator } \\
(100 \mathrm{~kW})\end{array}$ & $\begin{array}{c}\text { Starter-generator } \\
(100 \mathrm{~kW})[8],[9], \text { and } \\
\text { Applications }\end{array}$ \\
\hline \hline
\end{tabular}

isolated DC-links (type I), a common DC-link (type II), or a DC-link with a FC (type III). Table I preliminarily compares the performance of three dual inverter types seen in Fig. 4 and their applications in MEA. It can be seen from Fig. 4 only the dual inverter type I needs a bulky transformer to achieve isolation [31], [49]. This would increase the volume and weight of system significantly, which are not desired in MEA applications.

In this work, the indicator $k$ shown in Table I is employed to compare the voltage utilizations of the dual inverters. It is calculated by dividing the maximum output voltages from a dual inverter $V_{r e f, \max }$ over the voltage from its DClink voltage $V_{d c} / \sqrt{3}$ within the linear modulation region, as expressed in (5) [25].

$$
k=\sqrt{3} * V_{\text {ref, } \max } / V_{d c}
$$

The dual inverter type I uses two isolated DC-links where their voltages' sum is equivalent to $V_{d c}$, as shown in Fig. 4. Table I indicates that voltage utilization of the dual inverter type I could be less than one [43], [44]. This is due to the overcharge concerns, which will be elaborated in Section VI-A.

It can be seen from Table I that the output levels of dual inverter type I/III can be more than three [31], which is obviously an appealing feature. A higher number of output levels 
are conceivable for asymmetric supplies $\left(V_{d c, \text { main }} \neq V_{d c, \text { aux }}\right)$, and this study will be presented in Section V.

\section{B. Type II}

The dual inverter type II has the highest degree of fault tolerance and the double voltage utilization, as shown in Table I. References [47], [48] have taken those advantages by using the dual inverter type II for starter-generators. However, this configuration is suffered from the zero-sequence current (ZSC) circulating [50]. For a dual inverter, the ZSC is determined by the differential common-mode voltage (D-CMV) [45], [51], [52]. The expression of D-CMV is given in (6) [53].

$D-C M V=\frac{V_{A O}+V_{B O}+V_{C O}}{3}-\frac{V_{A^{\prime} O^{\prime}}+V_{B^{\prime} O^{\prime}}+V_{C^{\prime} O^{\prime}}}{3}$

Equations (3) and (6) indicate that D-CMV is identical to the voltage difference between the medium points of the voltage supplies on the two inverters, i.e. $O O^{\prime}$ in Fig. 2. To suppress this D-CMV, the dual inverter type II may degrade from multilevel to two-level operation [46], as shown in Table I. At the same time, the DC-link voltage utilization may also be affected [45]. A common methodology to virtually remove all ZSC is to implement the dual inverter type I or III [49].

\section{Type III}

Table I shows that the dual inverter type III has the advantages of the other two configurations in terms of multilevel output capability due to avoiding ZSC circulation and no need for any isolation circuitry since one bridge is floating. In particular, an attractive feature brought by type III is that its voltage utilization can be more than one thanks to the existence of the FC [24]. Researchers in [24] have applied the dual inverter with a FC for driving electromechanical actuators (EMAs) in the secondary flight control surface.

\section{Dual InVerter Design Freedom (2): Modulation SCHEMES}

A summary of the previously addressed modulation techniques for three types of dual inverters is reported in Table II. As stated in the introduction, the coupled modulation technique's primary benefit is that the multilevel output voltage can be guaranteed at all time. On the other hand, the resultant voltage on load for the decoupled method is unpredictable due to the decoupled modulation of the two inverters [91]. In this case, undesirable voltage steps in the inverter output can occur. The decoupled modulation scheme does however offer the main advantages of flexibility, fault tolerance and greater adaptability in terms of the various control objective functions for the drive. In the following, these two schemes are introduced using related previous works and publications.

\section{A. Coupled Modulation}

For coupled modulation, a dual inverter can be treated as a single multilevel converter. To reduce the switching actions, an alternate-sub-hexagonal centre (SHC) modulation scheme

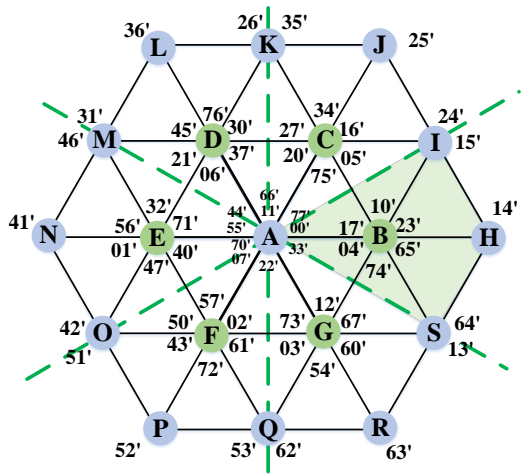

Fig. 5: Principle of the alternate-SHC modulation scheme for a symmetric dual inverter.

can be used to switch one inverter while clamping the other inverter to one state during a switching period [54], [55], [58]. Fig. 5 shows the mechanism of the alternate-SHC modulation scheme. In Fig. 5, the whole space vector diagram is divided into six sections, where the SHCs are marked by the circles $\mathrm{B}, \mathrm{C}, \mathrm{D}, \mathrm{E}, \mathrm{F}$ and $\mathrm{G}$ in green. As for each SHC, one inverter is switching whereas the other one is clamped, then the role is alternated for the next SHC. For instance, point B is the SHC of the quadrangle ASHI painted in light green in Fig. 5. Within this quadrangle, the applied switching states would be either 10', 11', 12', 13', 14', 15', 16', 17' (clamping the Main-Inv at 1 and switching the Aux-Inv) or 04', 14', 24', 34', 44', 54', 64', 74' (clamping the Aux-Inv at 4' and switching the MainInv). In particular, [55] conducts a thermal losses analysis of using the alternate-SHC modulation scheme, and [58] proves this technique is featured by equalizing losses between two inverters.

A power-sharing scheme between two inverters is established along with the relationship between the unbalanced sharing and the modulation index (M.I.) in [56]. In addition, researchers in [60]-[68] and [24], [31], [33]-[36], [38], [49], [84], [85] cope with the capacitor voltage regulation for the dual inverter type I and type III, respectively.

\section{B. Decoupled Modulation}

As mentioned before, the output voltage of a dual inverter is the difference between the voltages generated by two inverters. When the decoupled modulation is applied, the voltage reference $V_{\text {ref }}$ is synthesized into $V_{\text {ref,main }}$ and $V_{\text {ref,aux }}$ feeding into two inverters separately. This process can be expressed by (7),

$$
V_{\text {ref }} e^{j \theta}=V_{\text {ref,main }} e^{j \theta_{\text {main }}}-V_{\text {ref,aux }} e^{j \theta_{\text {aux }}}
$$

where $\theta_{\text {main }}$ and $\theta_{\text {aux }}$ are the angles of reference vectors $V_{\text {ref,main }}$ and $V_{\text {ref,aux }}$, respectively.

The schematic of reference vector synthesis is shown in Fig. 6. From (7) and Fig. 6, it can be observed that there are four user-defined variables. This allows for great control flexibility, which can then be taken advantage of. For example, [70] adjust the $\theta_{\text {main }}$ and $\theta_{\text {aux }}$, improving the output voltage profile for dual inverters. To reduce the output current ripple, 
TABLE II: Summary of modulation techniques for dual inverters in literature

\begin{tabular}{cc|cc}
\hline \hline \multirow{2}{*}{ Dual Inverter Design Freedom } & \multicolumn{2}{|c}{ (2) Modulation strategy } \\
& & Coupled (modulate as one whole inverter) & Decoupled (modulate as two separate inverters) \\
\hline \multirow{3}{*}{ (1) Configuration } & Type I & {$[54]-[68]$} & {$[44],[69]-[75]$} \\
& Type II & {$[45],[46],[76]-[81]$} & {$[82],[83]$} \\
& Type III & {$[24],[31],[33]-[35],[35],[36],[38],[49],[84],[85]$} & {$[33],[40],[42],[64],[86]-[90]$} \\
\hline \hline
\end{tabular}

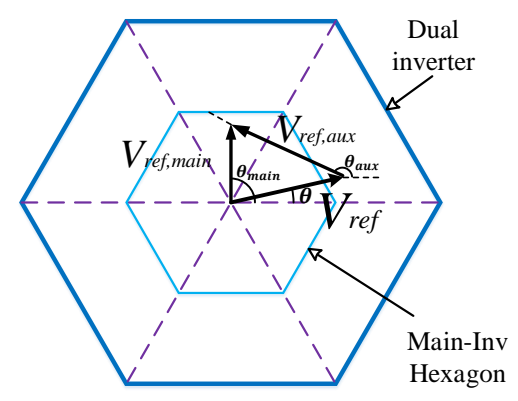

Fig. 6: Principle of decoupled modulation for a dual inverter.

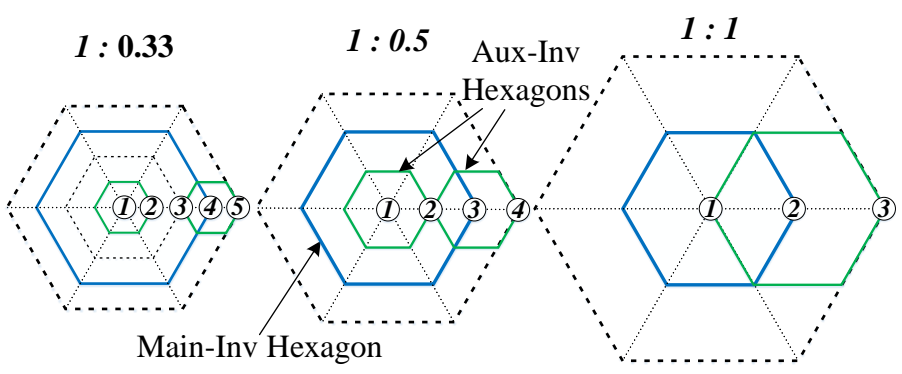

Fig. 7: Space vector diagram of the dual inverters with different voltage ratios.

[69] conducts an analytical study and then proposes a strategy based on the decoupled modulation.

Researchers in [44], [71]-[73] and [24], [31], [33]-[36], [38], [49], [85] deals with the capacitor voltage regulation for the dual inverter type I and type III, respectively.

Even though the decoupled modulation can bring excellent control flexibility, the undesirable voltage steps would inevitably be seen in the inverter output [24]. In consequence, the converter output performance is affected significantly.

\section{Dual Inverter Design Freedom (3): Voltage RATIO ASSIGNMENTS}

As revealed in Fig. 3, the output voltage from a dual inverter is the output voltage difference between the MainInv and the Aux-Inv. Therefore, the voltage ratio essentially alter the resulting space vectors' distribution of a dual inverter. In addition to that, the area of space vector diagram and the inverter output levels are both affected by the ratio choice. Fig. 7 shows the space vector diagram of the dual inverters with different voltage ratios. It can be observed that three, four, and five levels are achievable with ratios 1:1, 1:0.5, and 1:1, respectively.

It is worth of mentioning that the last design freedom is only applicable to the dual inverter type I and type III, while type
II has a common DC-link such that the ratio is fixed to one. In this section, the ratios considerations for the dual inverter type I and type III will be reviewed in order.

\section{A. Type I}

Initially, the dual inverter was mostly comprised of identical supply voltage for two inverters. This is known as the symmetrical voltage ratio (1:1). H.Stemmler demonstrated that dual two-level inverters with symmetric supplies had the equivalent performance of a three-level inverter in 1993 [92]. The advantages of asymmetric voltage supplies were first investigated in 1999 when a voltage ratio of 1:0.5 was primarily introduced to achieve a four-level operation in [60], [61]. However, this asymmetric ratio will raise the overcharge issue, which will be reviewed in Section VI-A.

\section{B. Type III}

One attractive freedom of the dual inverter type III is that the FC voltage can be flexibly controlled during the motor operation. If suitable voltage ratios are chosen, an increased number of output voltage levels [31], [33], [34], [38] or a boosted DC-link voltage utilization of dual inverters can be achieved [16], [40]-[42]. It has been revealed in [25] that the voltage ratio would define the 1) distribution of switching states; 2) area of space vector diagram; and 3) number of output levels. After selecting the ratios, the main issue is to properly regulate the $\mathrm{FC}$ voltage at that ratio.

In terms of utilizing the voltage ratios to increase the voltage levels, the ratio 1:0.5 is applied to provide three-level operation in [31], [38]. The researchers in [31], [38], [93] all adopted the coupled modulation. Despite guaranteeing the multilevel output waveform of dual inverters, their maximum output voltages are within the DC-link voltage due to limited regulation capabilities [31], [33], [36]-[38]. As a result, the FC voltages, which can be substantially beneficial for motor drives, are highly under-utilized [24].

Alternatively, the voltages ratios can be assigned to have a relatively large FC voltage, and thus the DC-link voltage utilization can be potentially high. However, the FC voltage could not be assigned extremely high as it has to below the capability of applied regulation methods. For example, a ratio of 1:2.5 is chosen to boost the voltage utilization in [40]. However, the six-step modulation technique is adopted, which naturally lowers the inverter output quality. Reference [42] has studied using the ratio $1: 2$, but its approach is perceived as a very complex control scheme with several non-linear regulators tuning [90]. Besides, the utilization improvement of $35 \%$ and $100 \%$ can be achieved using a voltage ratio of 


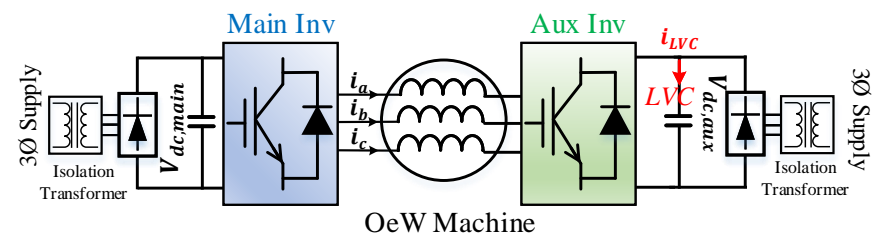

Fig. 8: Dual inverter type I (with isolated DC supplies).

1:1 [94] and [41], respectively. A varied voltage ratio was investigated in [16], which can enhance the DC-link voltage utilization by up to $60 \%$. All the FC regulation methods in [16], [40]-[42], [90], [94] apply the decoupled modulation strategy that separately allocates the reference voltages for two inverters, but this strategy causes undesired voltage steps at the inverter output resulting in distortions [24], [95]. In this case, the DC-link voltage utilization of dual inverters can be increased, but their output quality is significantly compromised.

The above shows that even selecting a suitable voltage ratio can potentially enhance the dual inverter performance, but this is significantly affected by the applied FC regulation method. The researchers firstly applied an advanced regulation method [24] on the dual inverter type III with 1:0.5, boosting the DClink voltage utilization by $50 \%$ along with four-level output [24]. Based on that, four more ratio candidates $(1: 2,1: 1$, 1:0.5, and 1:0.33) were considered in [25], while a strategy of integrating ratios 1:0.5 and 1:1 was addressed. Using this ratios strategy will allow the dual inverter to double voltage utilization while maintaining good power quality [25].

\section{Voltage Regulation for Dual InVERTERS}

As summarized in the previous sections, voltage regulation is crucial to the converter performance improvement. For instance, in the dual inverter with a FC, the main challenge is to regulate the FC's voltage to the desired value. Similarly, in the dual inverter with isolated asymmetric supplies, the capacitor at the lower-voltage side is at risk of being overcharged by the higher-voltage side. And for the one with a common DC-link, its challenge is to control the D-CMV properly. In this section, voltage regulation issues in dual inverters are explained, and the previously reported solutions are reviewed.

\section{A. Type I}

While an asymmetric dual inverter configuration enables the possibility to improve output quality (four-level operation), it however entails the risk of overcharging the low-voltage capacitor (LVC) on the Aux-Inv shown in Fig. 8. Such a situation will eliminate the voltage ratio and may cause safety issues of LVC on account of the charge accumulation [65], [73]. The overcharging issue at 1:0.5 ratio is reported initially in [62], and it is studied thoroughly in [44]. During the modulation process, the phase current flows into the LVC, and the overcharged capacitor will result in that the voltage ratio of 1:0.5 is not maintained. Under this condition, the phase voltage is distorted, rendering extra harmonic distortion into motors [44], [62]. Reference [73] proposed implementing

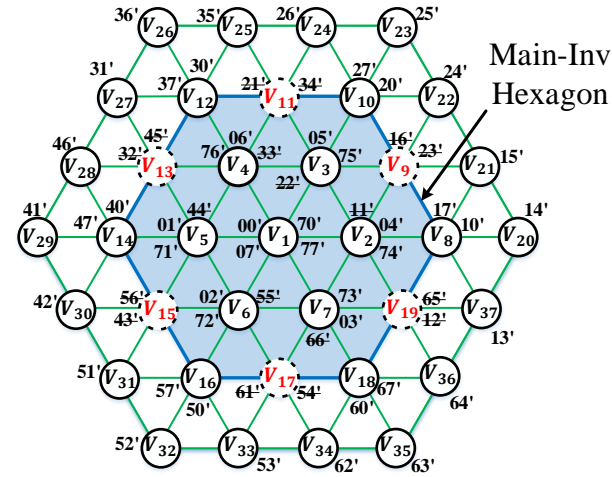

Fig. 9: The dual inverter type I with ratio 1:0.5 using the passive regulation method [62].
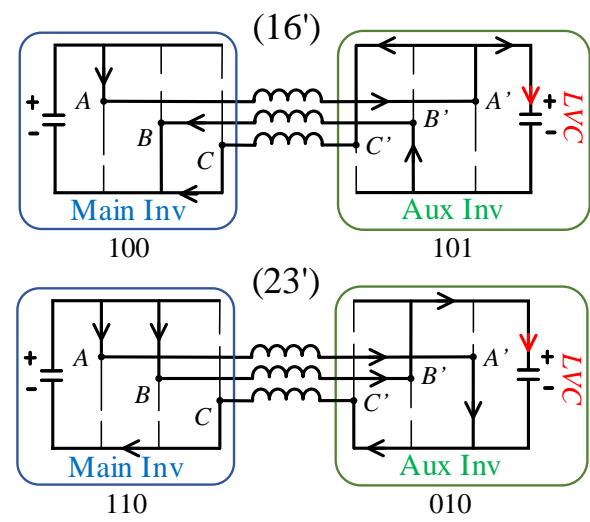

Fig. 10: Current flow schematics of using the overcharging states [44].

a fully controllable supply with bidirectional power flow as the DC-link on the Aux-Inv. This however comes at the cost of more complexity of hardware and of course an increased component count.

To remove the need for a bidirectional supply and also to solve the overcharging problem, there are generally two approaches found in literature, namely 1) through adjusting the modulation schemes [44], [62], [66], [68], [71], [73], and 2) by employing additional hardware [59], [63], [67], [72]. The first option is based on a selection of the switching states from analyzing the current flow associated with switching states to identify the states that may cause overcharging. Those states are then avoided for modulation process. This type of voltage regulation methods that assume the load current direction are denoted as the passive regulation method [24]. An illustration is given in Fig. 9. The states, such as 16' and 23' in Sector I marked with strikethroughs in Fig. 9, are regarded as the overcharging states and are therefore not considered. The current flows of using that two states are shown in Fig. 10, where the potential of overcharging the LVC can be observed [44]. The main drawback of such methods is that by reducing the number of vectors that can be used for modulation, such as $V_{9}$ in the red colour in Fig. 9. Under this case, the nearest three vectors (NTV) principle sometimes could not follow, which in turn lowers the output voltage quality.

A strategy to switch the Main-Inv while clamping the 


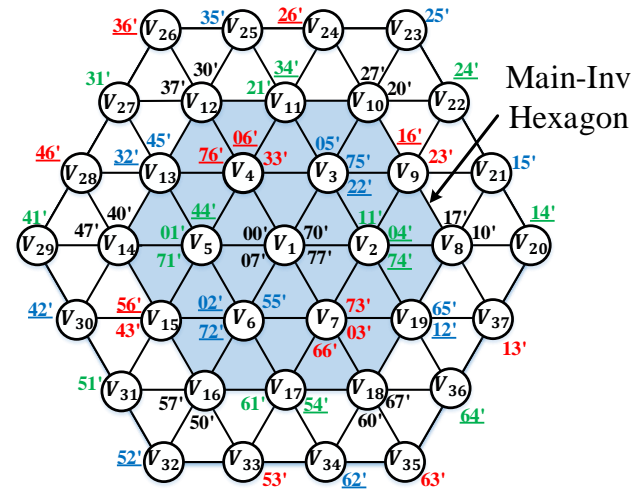

Fig. 11: The dual inverter type I with ratio 1:0.5 using the active regulation method [43].

Aux-Inv is presented in [66]. However, this method entails a larger modulation area, which implies that the harmonic distortion in the inverter output may be worsened. To improve power quality, a coupled discontinuous carrier-based pulse width modulation (PWM) technique is established in [68]. However, the modulating signal in this method intersects with all the carrier signals throughout the whole M.I. region. It implies that the switching actions could be considerably high, thus increasing the switching losses. In particular, the major problem of passive regulation is that their analysis in [44], [62], [68], [71] takes the assumption of current direction, which is actually affected by the load power factor (PF) [24].

An enhanced version of passive regulation, namely the active regulation, was addressed in [43]. This scheme will actively choose the suitable states according to the regulation need with the help of the measured phase current values. The active regulation method starts with characterizing all the switching states by their resulting currents into the LVC. An example of the dual inverter with ratio 1:0.5 using active regulation method is shown in Fig. 11. Defining the current flowing into the Aux-Inv as the positive direction, the switching states causing the negative current flow is underlined in Fig. 11. In addition to that, the line colour highlights the flow path of different phase currents. The green colour represents the flow path of current $i_{a}$, the red colour indicates the path of current $i_{b}$, and blue shows the path of current $i_{c}$. With an appropriate switching states' selection, a suitable current flow can be determined to avoid overcharging the LVC. For instance, assuming the vector $V_{9}$ is chosen for modulation, there are two switching states 23' and 16' in Fig. 11 that can be used for modulation and one of those two will not cause the overcharging depending on the current direction. Compared to the passive regulation approach shown in Fig. 9, the vector $V_{9}$ associated states 16' and 23' are regarded as the overcharging states that are forbidden to use for modulation purposes. In contrast, when active regulation scheme is adopted, vector $V_{9}$ can be applied, such that the NTV algorithm can be followed and the inverter output quality would not be affected.

Reference [73] proposes a modulation technique, unequal reference sharing algorithm based on carrier-based PWM that naturally regulates the LVC voltage. The mean value sign of the current $i_{L V C}$, i.e. the current acting on the LVC showed in

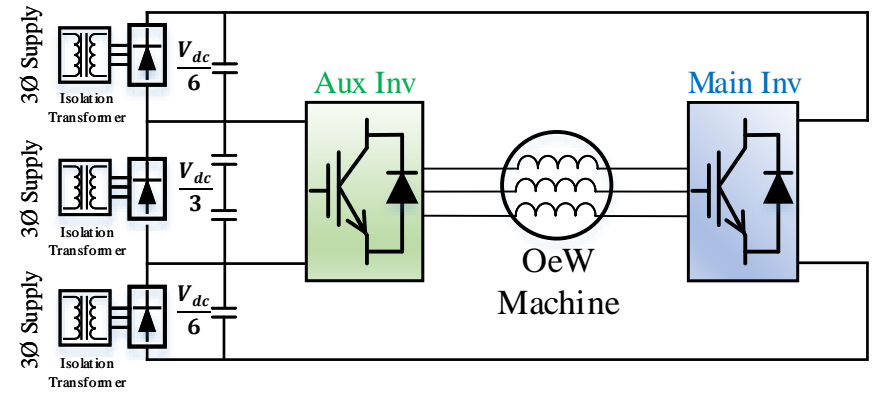

Fig. 12: Dual inverter with a nested rectifier-inverter reported in [63].
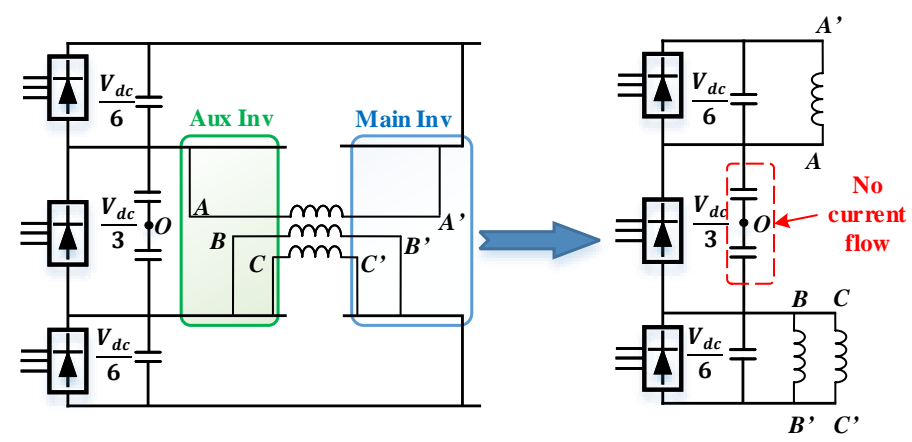

Fig. 13: Motor phases connection for state 11' in the dual inverter with a nested rectifier-inverter.

Fig. 8, is analyzed through a numerical iteration. It is observed that $i_{L V C}$ would have a negative mean value when the method in [73] implements. However, this method attributes to the decoupled modulation so undesirable voltage steps can be witnessed, resulting in a deteriorated output voltage waveform.

For the hardware solution, a structure of nested rectifierinverter is proposed in [63] (see Fig. 12), and it is further revised in [59]. In this structure, the Aux-Inv with lowervoltage DC-link is nested within higher-voltage DC-link that feeds the Main-Inv. Subsequently, based on this structure, more advanced modulation schemes are addressed to achieve a boosted voltage utilization for the $6 n$-pole OeW motor in [72], or suppress the ZSC in an average sense in [67]. The feasibility of the structure in Fig. 12 is explained through Fig. 13. In Fig. 13, a particular instance of using the state $11^{\prime}$ is shown. Fig. 13 shows the connection of motor phases to the LVC for the state 11'. It is evident that the configuration of a nested rectifier-inverter successfully achieves the prevention of overcharging problem. However, the main drawback of this solution is that it needs one more isolated DC supply when compares to the scheme of Fig. 12 with Fig. 8. Naturally, employing a more complicated structure with an increased component count would considerately increase the volume and the cost of the motor drive system [66], [68].

\section{B. Type II}

Fig. 14 shows that the dual inverter type II share one common DC-link. The primary concern of this topology is the ZSC current, $i_{Z S C}$ in Fig. 14, may circulate the system. It would increase the value of the phase current without any 


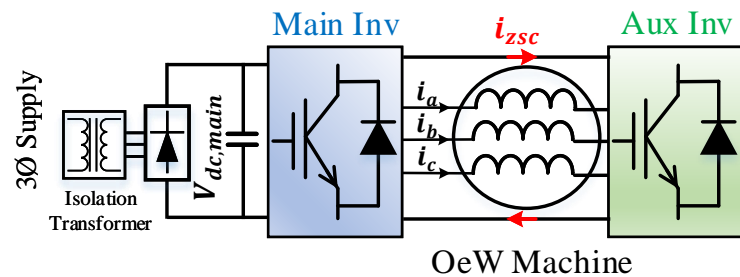

Fig. 14: Dual inverter type II (with a common DC-link).

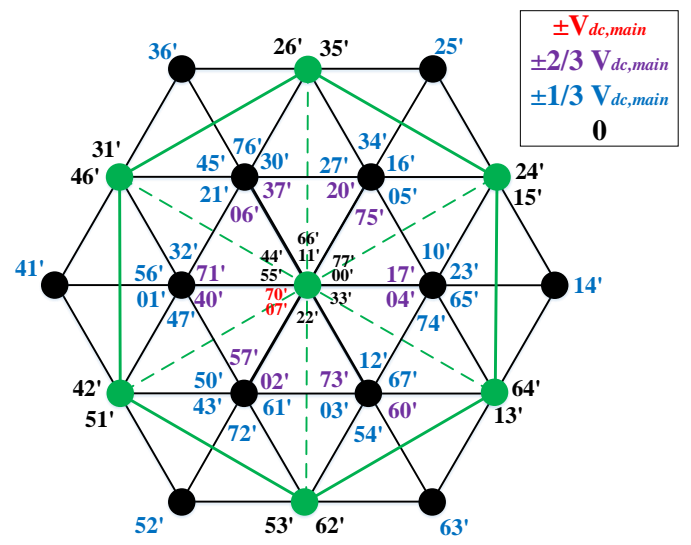

Fig. 15: D-CMV by the dual inverter type II.

contribution to the real power [96]. Thus, significant effort has been made to eliminate or reduce D-CMV [45], [46], [48], [48], [77]-[81].

In Fig. 15, the D-CMV generated by the dual inverter type II is shown. This figure can be obtained by using Equation (6). Since the two inverters share one voltage source, this implies that $V_{d c, \text { main }}=V_{d c, \text { aux }}$. Fig. 15 shows that switching states can lead to seven different levels of D-CMV, i.e. 0, $\pm \frac{1}{3} V_{d c, \text { main }}, \pm \frac{2}{3} V_{d c, \text { main }}$ and $\pm V_{d c, \text { main }}$. In [45], [47], [51], [52], [79]-[81], only the switching states that results in zero D-CMV are utilized for modulation purposes, and these are shown with the green points in Fig. 15. An alternate-SHC scheme is presented in [79]-[81], aiming to distribute the losses evenly between two inverters. The zero states are redistributed to suppress D-CMV [46], [77]. Reference [77] claims that if the angle difference of $\theta_{\text {main }}$ and $\theta_{\text {aux }}$ is $120^{\circ}$ (see Fig. 6), D-CMV can be virtually eliminated.

However, similar to the CMV reduction in a two-level inverter, all the D-CMV elimination methods for a dual inverter would inevitably sacrifice the output quality. As shown in Fig. 15 , the output level is degraded from three-level to two-level, fulfilling the zero D-CMV. More importantly, the vertices of the space vector diagram (14', 25', 36', 41', 52', and 63') in Fig. 15 cannot be used for modulation, thus reducing the voltage utilization by $13.4 \%$ [45], [47], [52].

\section{Type III}

Compared to the dual inverter type I and II, type III integrates the advantage of virtually no ZSC circulation or any need for isolation circuitry. However, the major challenge with this configuration is to maintain the $\mathrm{FC}$ voltage due to

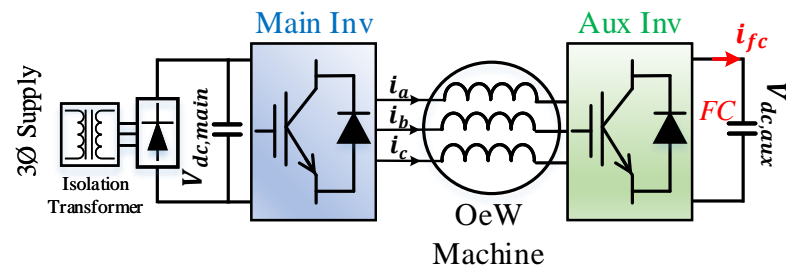

Fig. 16: Dual inverter type III (with a FC).

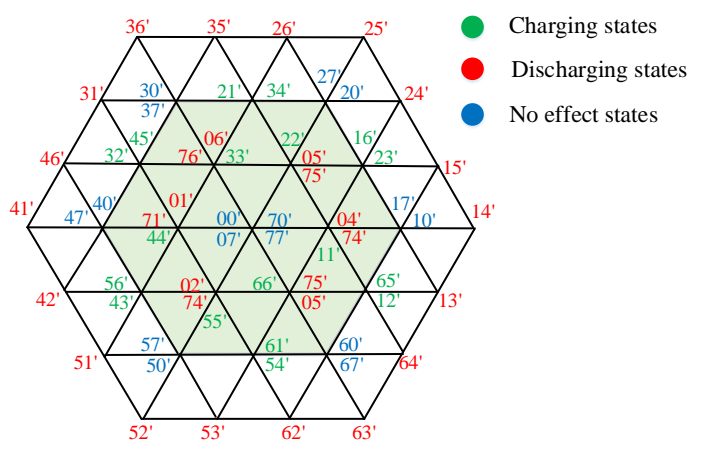

Fig. 17: Dual inverter type III with 1:0.5 using the passive regulation [31].

its floating nature [24]. References [31], [38] claim that if achieving the FC voltage regulation and multilevel operation at the same time, the performance of the dual inverter with a FC has to be compromised.

In [31], [33], [35], [36], [38], [85], the coupled modulation method is selected where from a modulation perspective, the dual inverter is considered as a whole inverter. The effect of switching states on the capacitor voltage is analyzed in steady-state operation [31], [36], [85]. The method proposed in [31] is shown in Fig. 17, where all the switching states are divided into three groups: the charging states in green, the discharging states in red and the no effect states in blue. In [31], there are no charging states at the outermost space vector diagram, and thus it can be said that the voltage utilization is constrained within the DC-link voltage of the Main-Inv, i.e. the green hexagon in Fig. 17. Under this condition, the capacitor voltage, which can be substantially beneficial for motor drive applications, is under-utilized [24], [91]. On the other side, the voltage output level is reduced from four to three. The analysis in [31], [36], [85] assumes the current direction, but the instantaneous current that flows into the capacitor is practically defined by the motor PF angle [33], [38]. Essentially, these methods [31], [36], [85] are attributed to passive regulation without the need for load current information.

In [38], a regulation scheme that involves the feedback of the motor PF angle is developed. Besides, a redundant state selection table that requires current feedback based on the level-shifted PWM technique is investigated in [33], [35]. A particular M.I. zone is identified for the reference vector of a dual inverter in [34]. To operate within that zone and supply the required voltage at the same time, a variable DC source is necessary. This would increase the complexity of the system and may raise instability problems.

Similar to the active regulation method developed for the 
dual inverter type I (see Section VI-A), it has been extended for type III in [24]. Compared to avoiding the overcharge issues by selecting the states associated with negative currents, FC voltage regulation schemes appear to be more complicated. This is because the associated current needs to be carefully controlled such that the FC voltage can be maintained at the desired level. In [24], the capacitor charge variations by using all switching states are analytically derived. Depending on the difference between the measured FC voltage and its reference value, the dwell time among redundant states will be allocated. Compared to using the passive regulation, the advantages of proposed active schemes include a boosted voltage utilization and improved output quality [24], [25].

The FC voltage regulation also can be achieved using decoupled modulation. In [29], [33], [40], [42], [87], [90], the $\mathrm{FC}$ is treated as a reactive power compensator such that it accommodates all the reactive power where the active power into FC should be zero at the steady state. Under this consideration, the FC voltage regulation could be readily accomplished by controlling the active power flowing into FC via a proportional-integral controller. In [88], the M.I. of reference vector for the Aux-Inv is maintained at the maximum, and then the M.I. of reference vector for the MainInv is employed for the FC voltage regulation. In addition, one particular control freedom of the decoupled modulation is to vary the angle between two reference vectors, which is taken advantage of regulating FC voltage in [16]. However, as emphasized in Section IV-B, the decoupled modulation would lead to undesirable voltage steps, which deteriorate the output performance [91].

In [86], a modulation strategy that the Main-Inv utilizes the staircase modulation to switch at the fundamental frequency whereas the Aux-Inv operates at high-frequency PWM is reported. The FC voltage is regulated by adjusting the firing angle of the fundamental voltage reference for the MainInv. This scheme could considerably reduce the switching losses of the system since the Main-Inv is operated at the fundamental frequency. However, it is not suitable for some operation regions, and also it is perceived as a relatively complex implementation [85].

\section{PERformance EVAluation on Dual InVERTERS}

In this section, the performance of dual inverter topologies in terms of the fault-tolerant capability, the inverter output power quality and the DC-link voltage utilization is assessed. This is followed a final recommendation of the most suitable topologies for MEA applications.

\section{A. Fault-Tolerant Capability}

The fault-tolerant capability is of great interest for safetycritical aerospace applications. As seen in previous discussions, the DC-link voltage utilization and the inverter output power quality may be affected by all three design freedom of dual inverters. However, the fault-tolerant capabilities of dual inverters only depend on their configurations.

Among three types of dual inverters, type II has the highest degree of fault tolerance as it is symmetrical [98], [99].

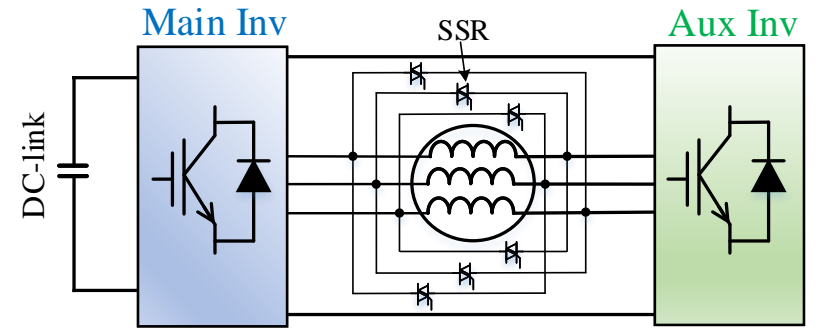

Fig. 18: Reported dual inverter type II structure with the enhanced fault tolerance in [97].

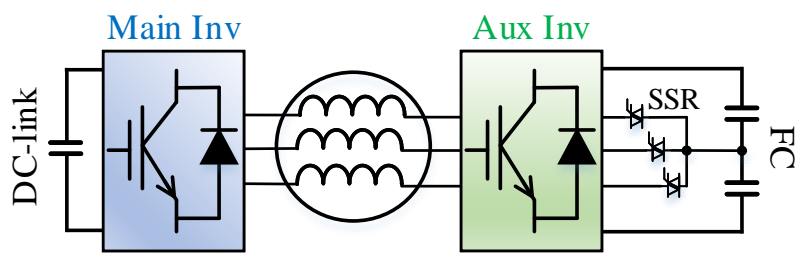

Fig. 19: Reported dual inverter type III structure with the enhanced fault tolerance in [19]-[21].

Researchers in [100] proposed a predictive control that can well compensate the ZSC under the case of single-phase openfault. It was proven that this particular configuration could accommodate up to six diode/switch open-circuit faults using the proposed post-fault zero-sequence current injection in [98]. To enhance the fault-tolerant capability of dual inverter type II, six additional bidirectional solid-state relays (SSRs) are added in [97], as shown in Fig. 18. For this structure, the faulttolerant operation can be realized by winding reconnection for open-circuit fault in up to three legs, without lowering the output capacity [97].

Dual inverter type I exhibits a slightly lower fault tolerance capability to type II. Once one inverter, Main-Inv or Aux-Inv, is failed, its three bridges can be shorted, forming a neutral point [101], [102]. In comparison, type III exhibits relatively limited fault tolerance, where the faults can be resolved only for the switches on the Aux-Inv [25], [37]. When the switches on the Aux-Inv are failed; its three bridges can then be shorted, forming a neutral point [31]. The fault-tolerant capability of the dual inverter type III can be enhancing by including three SSRs, as shown in Fig. 19, where the Aux-Inv can be reconfigured to a four-switch inverter with one-phase fault [19]-[21].

\section{B. Voltage Utilization and Power Quality}

After studying fault tolerance, this part will focus on the rest two performance aspects. Table III summarizes all the stateof-the-art research on dual inverters in literature. With three exclusive design freedom featured by dual inverters and different voltage regulation methods, the converter performance in terms of the power quality through the number of output levels and the voltage utilization can be varied, as shown in Table III.

According to Table III, the dual inverter type II contributes to the highest voltage utilization of $1.73 V_{d c}$, but with relatively 
TABLE III: Summary of all the studied dual inverters in literature

\begin{tabular}{|c|c|c|c|c|c|c|}
\hline \multicolumn{3}{|c|}{ Dual Inverter Design Freedom } & \multirow{2}{*}{ Voltage Regulation Method } & \multicolumn{2}{|c|}{ Performance } & \multirow{2}{*}{ Paper } \\
\hline (1)Configuration & $\begin{array}{l}\text { (2) Modulation } \\
\text { strategy }\end{array}$ & $\begin{array}{l}\text { (3) Voltage } \\
\text { ratios }\end{array}$ & & $\begin{array}{c}\text { DC-link Voltage } \\
\text { Utilization } \boldsymbol{k}\end{array}$ & $\begin{array}{l}\text { Output Quality } \\
\text { (level number) }\end{array}$ & \\
\hline \multirow{3}{*}{ Type I } & \multirow[b]{2}{*}{ Coupled } & $1: 1$ & N.A. & \multirow[b]{2}{*}{1} & High (3) & [57]-[59] \\
\hline & & $1: 0.5$ & $\begin{array}{l}\text { Passive regulation } \\
\text { Active regulation }\end{array}$ & & $\begin{array}{c}\text { High }(<4) \\
\text { Very high }(4)\end{array}$ & $\begin{array}{l}{[44],[68],[71]} \\
{[43]}\end{array}$ \\
\hline & Decoupled & $\begin{array}{c}1: 1 \\
1: 0.5 \\
\end{array}$ & $\begin{array}{c}\text { N.A. } \\
\text { Unequal reference voltages sharing }\end{array}$ & 1 & Low & $\begin{array}{l}{[69],[70]} \\
{[73]}\end{array}$ \\
\hline Type II & $\begin{array}{l}\text { Decoupled } \\
\text { Coupled }\end{array}$ & $1: 1$ & $\begin{array}{l}\text { Apart } \theta_{\text {main }} \text { and } \theta_{\text {aux }} \text { by } 120^{\circ} \\
\text { Utilize states with zero D-CMV }\end{array}$ & $\begin{array}{c}<2 \\
1.73\end{array}$ & $\begin{array}{c}\text { Low } \\
\text { Medium (2) }\end{array}$ & $\begin{array}{l}{[77]} \\
{[51],[52],[81]}\end{array}$ \\
\hline \multirow{8}{*}{ Type III } & \multirow{5}{*}{ Decoupled } & $1: 2.5$ & \multirow{5}{*}{ Reactive power control } & $>1$ & \multirow{5}{*}{ Low } & {$[40]$} \\
\hline & & $1: 1$ & & Up to $\sim 1.3$ & & {$[42]$} \\
\hline & & $1: 1$ & & $1-1.35$ & & [94] \\
\hline & & Varied & & $1-1.6$ & & [16], [90] \\
\hline & & $1: 2$ & & Up to 2 & & [41] \\
\hline & \multirow{3}{*}{ Coupled } & \multirow{2}{*}{$1: 0.5$} & Passive regulation & 1 & High (3) & [31], [38], [93] \\
\hline & & & Active regulation & $1.1-1.5$ & Very high (4) & [24] \\
\hline & & $1: 0.5+1.1$ & Active regulation & $1.1-2$ & Very high (3-4) & [25] \\
\hline
\end{tabular}

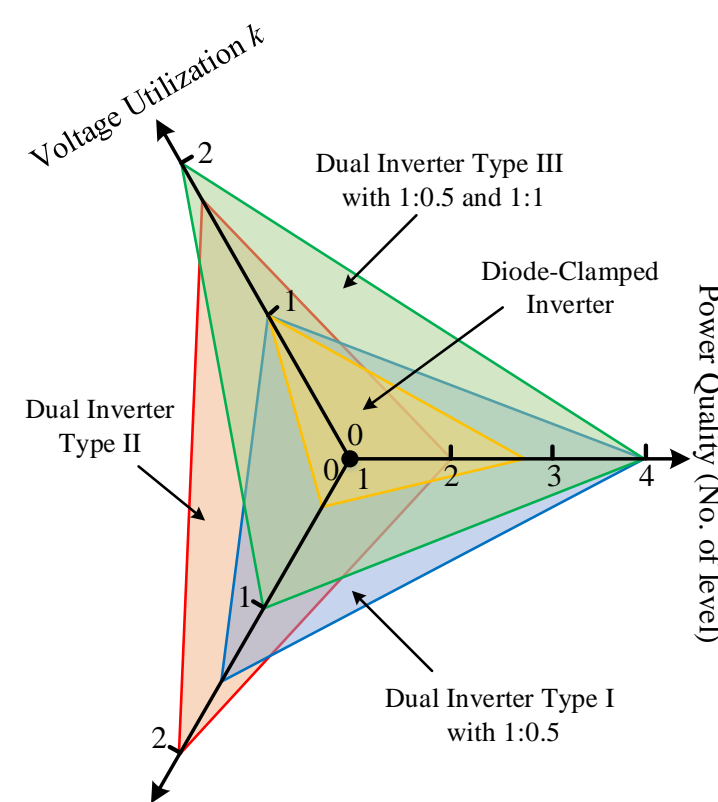

Fault-Tolerant Capability

Fig. 20: Overall assessment of inverter topologies with 12 switches for MEA applications.

low output quality (two-level operation) on account of avoiding the ZSC [51], [52], [81]. Alternatively, the dual inverter type III with the ratios 1:1 and 1:0.5 using coupled modulation and active regulation could achieve a comparable utilization [43], as shown in Table III. Considering the power quality aspect in Table III, the dual inverter type I with 1:0.5 and type III with the ratio ratios 1:1 and 1:0.5 comprise the best results with a perfect four-level operation [25].

\section{Final Assessment}

Fig. 20 selects three dual inverter candidates after the overall assessment in the above discussion. The chosen inverters are dual inverter type I with the voltage ratio 1:0.5 in the blue triangle, dual inverter type II in the red triangle and dual inverter type III with the voltage ratio 1:0.5 and 1:1 in the green triangle, as shown in Fig. 20. Besides, the DCI in the yellow colour, a representative of multilevel inverters, is also included in Fig. 20 as the benchmark.

It can be seen from Fig. 20 that the dual inverter type III with 1:0.5 and 1:1 performs the best in terms of the output power quality and the DC-link voltage utilization. As for faulttolerant capabilities, the dual inverter type II is the strongest, following by type I, type III, while the DCI is the lowest, as shown in Fig. 20.

A DCI is supposed to generating a three-level output voltage, but it suffers from the neutral point fluctuation. To balance the DC-link capacitors while retaining the full DClink voltage utilization, the DCI has to lower the output quality [13], [15], as shown in Fig. 20. It was reported that DCI has a very limited fault tolerance where only one short-circuit fault can be accommodated [103].

It is undoubted that from the point of view of finding a suitable motor drive, dual inverter type III with 1:0.5 and $1: 1$ is the best choice. A considerably high-voltage utilization together with maintaining good power quality are achievable at the same time. This topology can be particularly beneficial for MEA applications, adopted with relatively low dc-link voltages. Higher speed motor drives are an obvious choice fulfilling the stringent requirement of MEA applications in terms of high power density coupled with higher efficiency, but their wide-speed operation is essentially subject to the DC bus voltage onboard. By fully exploiting the FC voltage, the machines' constant-torque region can be boosted, allowing 
motors to minimize their weight and volume considerably [24], [25]. Besides, the machines' constant-power region also can be extended as the FC can be regarded as a reactive power compensator [104]-[106].

On the other side, the standard two-level converter still dominates in MEA, while applying the three-level converter such as DCI with better power quality have been intensively discussed [5], [6], [13], [15], [107]. It is apparent from Fig. 20 that the dual inverter type III with $1: 0.5$ and $1: 1$ can provide superior output quality compared to using a DCI. This excellent harmonic profile can potentially reduce machines losses [108]. Above all, the dual inverter type III with 1:0.5 and $1: 1$ is the optimal topology driving the high-performance machines.

However, if fault tolerance is the most vital consideration, dual inverter type II will be the best choice. And when taking the output power quality into account, the dual inverter type I with 1:0.5 may stand out. However, it is worth mentioning that this particular configuration needs isolation between two power supplies. This means that the dual inverter type $\mathrm{I}$ is more suitable for the system powering by the batteries with natural isolation.

\section{IMPLEMENTATIONS OF DUAL INVERTERS IN MEA}

\section{A. Suitable Applications}

The reliability of power electronics has been identified as one of the most crucial challenges for their promotion in MEA applications [109]. The key areas for safety-critical consideration are generators, primary flight surface control, landing system, and fuel pumps [10]. Therefore, dual inverter type II is recommended due to its extremely strong fault tolerance. For the electric systems with lower reliability requirement, such as the secondary actuators, the dual inverter type III can be selected. This topology may be broadly used once enhancing its fault-tolerant capability by involving three more SSRs, as seen in [19]-[21]. However, the weight increase and power consumption of those three SSRs need to be further investigated.

\section{B. Switching Device Choice}

In the last two decades, the commercial application of silicon carbide ( $\mathrm{SiC}$ ) devices are prone to have profound implications on the development of MEA applications [1], [5], [107]. Compared to silicon ( $\mathrm{Si}$ ) -based devices, the ones using $\mathrm{SiC}$ can operate at greater voltage, higher temperature, faster switching frequency [107]. Researchers in [8], [9] studied the performance of dual inverter type II with a full $\mathrm{SiC}$ and with hybrid $\mathrm{SiC}$ and $\mathrm{Si}$ solutions for starter-generator applications in MEA. For the hybrid one, the Main-Inv is built by Si-IGBT switching at the fundamental frequency, while the Aux-Inv is constituted by SiC-MOSFET switching at higher frequencies [47], [48]. This hybridization can reduce the converter loss compared to the full $\mathrm{SiC}$ solution but with a compromised output quality [110]. However, considering the whole drive system, a full $\mathrm{SiC}$ solution is still recommended due to their faster switching frequencies such that higher speed machines are feasible [6], [12], [111].

\section{Future Trends}

Compared to a standard machine, there is no additional manufacture, cost challenge or extra magnetic modifications raised by the OeW machines [110], [112]. In fact, the OeW machines fed by dual inverters have been extensively used in commercial hybrid-/all- electric vehicles with similar DClink voltage constraints as seen in MEA [113]. In many cases, the aircraft are utilizing inverter topologies from automotive applications [1]. Therefore, the OeW motor drives penetration can be identified as a promising trend for MEA applications in the near future.

\section{SUMMARY}

In this paper, a comprehensive technical review of dual inverter topologies for motor drives in MEA applications was conducted. The operation principle, modulation schemes, capacitor voltage regulation, and the voltage ratio considerations of dual inverters were elaborated in sequence. To identify an optimal power inverter configuration, the dual inverters in three types with all applicable voltage ratios were considered. Their performance covering the DC-link voltage utilization, the output quality and the fault-tolerant capability were assessed. After a holistic comparison, the dual inverter type III with 1:0.5 and 1:1 was recommended due to its high voltage utilization coupled with maintaining good power quality. And the dual inverter type II was preferred in case the fault tolerance is the essential requirement. It has been proven that those two dual inverter topologies have emerged as significantly competitive choices against other multilevel inverter topologies for MEA applications.

\section{REFERENCES}

[1] L. Dorn-Gomba, J. Ramoul, J. Reimers, and A. Emadi, "Power electronic converters in electric aircraft: Current status, challenges, and emerging technologies," IEEE Transactions on Transportation Electrification, vol. 6, no. 4, pp. 1648-1664, 2020.

[2] V. Madonna, P. Giangrande, and M. Galea, "Electrical power generation in aircraft: Review, challenges, and opportunities," IEEE Transactions on Transportation Electrification, vol. 4, no. 3, pp. 646-659, 2018.

[3] P. Giangrande, A. Galassini, S. Papadopoulos, A. Al-Timimy, G. L. Calzo, M. Degano, M. Galea, and C. Gerada, "Considerations on the development of an electric drive for a secondary flight control electromechanical actuator," IEEE Transactions on Industry Applications, vol. 55, no. 4, pp. 3544-3554, 2019.

[4] C. Wang, T. Yang, H. Hussaini, Z. Huang, and S. Bozhko, "Power quality improvement using an active power sharing scheme in more electric aircraft," IEEE Transactions on Industrial Electronics, 2021.

[5] T. C. Cano, A. Rodrmguez, D. G. Lamar, I. Castro, L. AlbiolTendillo, Y. F. Khalil, and P. Kshirsagar, "Future of electrical aircraft energy power systems: An architecture review," IEEE Transactions on Transportation Electrification, 2021.

[6] G. Buticchi, S. Bozhko, M. Liserre, P. Wheeler, and K. Al-Haddad, "On-board microgrids for the more electric aircraft-technology review," IEEE Transactions on Industrial Electronics, vol. 66, no. 7, pp. 55885599, 2018.

[7] J. Chen, C. Wang, and J. Chen, "Investigation on the selection of electric power system architecture for future more electric aircraft," IEEE Transactions on Transportation Electrification, vol. 4, no. 2, pp. 563-576, 2018.

[8] G. L. Calzo, P. Zanchetta, C. Gerada, A. Lidozzi, M. Degano, F. Crescimbini, and L. Solero, "Performance evaluation of converter topologies for high speed starter/generator in aircraft applications," in Industrial Electronics Society, IECON 2014-40th Annual Conference of the IEEE, pp. 1707-1712. IEEE, 2014. 
[9] G. L. Calzo, P. Zanchetta, C. Gerada, A. Gaeta, and F. Crescimbini, "Converter topologies comparison for more electric aircrafts high speed starter/generator application," in 2015 IEEE Energy Conversion Congress and Exposition (ECCE), pp. 3659-3666. IEEE, 2015.

[10] W. Cao, B. C. Mecrow, G. J. Atkinson, J. W. Bennett, and D. J. Atkinson, "Overview of electric motor technologies used for more electric aircraft (MEA)," IEEE Transactions on Industrial Electronics, vol. 59, no. 9, pp. 3523-3531, 2012.

[11] C. Gu, H. Yan, J. Yang, G. Sala, D. De Gaetano, X. Wang, A. Galassini, M. Degano, X. Zhang, and G. Buticchi, "A multiport power conversion system for the more electric aircraft," IEEE Transactions on Transportation Electrification, vol. 6, no. 4, pp. 1707-1720, 2020.

[12] M. Lukic, P. Giangrande, A. Hebala, S. Nuzzo, and M. Galea, "Review, challenges, and future developments of electric taxiing systems," IEEE Transactions on Transportation Electrification, vol. 5, no. 4, pp. 14411457, 2019.

[13] F. Guo, T. Yang, A. Diab, S. Yeoh, S. Bozhko, and P. Wheeler, "An enhanced virtual space vector modulation scheme of three-level npc converters for more-electric-aircraft applications," IEEE Transactions on Industry Applications, DOI 10.1109/TIA.2021.3085798, 2021.

[14] C. Li, T. Yang, P. Kulsangcharoen, G. L. Calzo, S. Bozhko, C. Gerada, and P. Wheeler, "A modified neutral-point balancing space vector modulation technique for three-level neutral point clamped converters in high speed drives," IEEE Transactions on Industrial Electronics, vol. 66, no. 2, pp. 910-921, 2019.

[15] F. Guo, T. Yang, C. Li, S. Bozhko, and P. Wheeler, "Active modulation strategy for capacitor voltage balancing of three-level neutralpoint-clamped converters in high-speed drives," IEEE Transactions on Industrial Electronics, DOI 10.1109/TIE.2021.3065605, 2021.

[16] J. Ewanchuk, J. Salmon, and C. Chapelsky, "A method for supply voltage boosting in an open-ended induction machine using a dual inverter system with a floating capacitor bridge," IEEE Transactions on Power Electronics, vol. 28, no. 3, pp. 1348-1357, 2013.

[17] X. Lang, T. Yang, Z. Huang, C. Wang, Z. Wang, S. Bozhko, and P. Wheeler, "Stability improvement of onboard hvdc grid and engine using an advanced power generation center for the more-electric aircraft," IEEE Transactions on Transportation Electrification, DOI 10.1109/TTE.2021.3095256, pp. 1-1, 2021.

[18] L. Dang, N. Bernard, N. Bracikowski, and G. Berthiau, "Design optimization with flux weakening of high-speed pmsm for electrical vehicle considering the driving cycle," IEEE Transactions on Industrial Electronics, vol. 64, no. 12, pp. 9834-9843, 2017.

[19] W. Zhao, P. Zhao, D. Xu, Z. Chen, and J. Zhu, "Hybrid modulation fault-tolerant control of open-end windings linear vernier permanentmagnet motor with floating capacitor inverter," IEEE Transactions on Power Electronics, vol. 34, no. 3, pp. 2563-2572, 2018.

[20] W. Zhao, Z. Chen, D. Xu, J. Ji, and P. Zhao, "Unity power factor fault-tolerant control of linear permanent-magnet vernier motor fed by a floating bridge multilevel inverter with switch fault," IEEE Transactions on Industrial Electronics, vol. 65, no. 11, pp. 9113-9123, 2018.

[21] W. Zhao, B. Wu, Q. Chen, and J. Zhu, "Fault-tolerant direct thrust force control for a dual inverter fed open-end winding linear vernier permanent-magnet motor using improved SVPWM," IEEE Transactions on Industrial Electronics, vol. 65, no. 9, pp. 7458-7467, 2018.

[22] S. S. Yeoh, M. Rashed, M. Sanders, and S. Bozhko, "Variable-voltage bus concept for aircraft electrical power system," IEEE Transactions on Industrial Electronics, vol. 66, no. 7, pp. 5634-5643, 2018.

[23] M. G. Majumder, R. Rakesh, M. Imthias, K. Gopakumar, U. Loganathan, and W. Jarzyna, "Extending the linear modulation range to full base speed independent of load power factor for a multilevel inverter fed im drive," IEEE Transactions on Industrial Electronics, vol. 67, no. 11, pp. 9143-9152, 2019.

[24] Z. Huang, T. Yang, P. Giangrande, S. Chowdhury, M. Galea, and P. Wheeler, "An active modulation scheme to boost voltage utilization of the dual converter with a floating bridge," IEEE Transactions on Industrial Electronics, vol. 66, no. 7, pp. 5623-5633, 2019.

[25] Z. Huang, T. Yang, P. Giangrande, S. Chowdhury, M. Galea, and $\mathrm{P}$. Wheeler, "Enhanced performance of dual inverter with a floating capacitor for motor drive applications," IEEE Transactions on Power Electronics, vol. 36, no. 6, pp. 6903-6916, 2020.

[26] X. Lang, T. Yang, Z. Wang, C. Wang, S. Bozhko, and P. Wheeler, "Fault tolerant control of advanced power generation center for moreelectric aircraft applications," IEEE Transactions on Transportation Electrification, DOI 10.1109/TTE.2021.3093506, pp. 1-1, 2021.

[27] A. Salem, H. Van Khang, K. G. Robbersmyr, M. Norambuena, and J. Rodriguez, "Voltage source multilevel inverters with reduced device count: Topological review and novel comparative factors," IEEE Transactions on Power Electronics, vol. 36, no. 3, pp. 2720-2747, 2020.

[28] S. Kouro, M. Malinowski, K. Gopakumar, J. Pou, L. G. Franquelo, B. Wu, J. Rodriguez, M. A. Pérez, and J. I. Leon, "Recent advances and industrial applications of multilevel converters," IEEE Transactions on Industrial Electronics, vol. 57, no. 8, pp. 2553-2580, 2010.

[29] M. S. Toulabi, J. Salmon, and A. M. Knight, "Design, control, and experimental test of an open-winding IPM synchronous motor," IEEE Transactions on Industrial Electronics, vol. 64, no. 4, pp. 2760-2769, 2017.

[30] B. P. Reddy and S. Keerthipati, "A multilevel inverter configuration for an open-end-winding pole-phase-modulated-multiphase induction motor drive using dual inverter principle," IEEE Transactions on Industrial Electronics, vol. 65, no. 4, pp. 3035-3044, 2018.

[31] S. Chowdhury, P. W. Wheeler, C. Patel, and C. Gerada, "A multilevel converter with a floating bridge for open-end winding motor drive applications," IEEE Transactions on Industrial Electronics, vol. 63, no. 9 , pp. 5366-5375, 2016.

[32] B. Wang, G. Localzo, G. El Murr, J. Wang, A. Griffo, C. Gerada, and T. Cox, "Overall assessments of dual inverter open winding drives," in Electric Machines \& Drives Conference (IEMDC), 2015 IEEE International, pp. 1029-1035. IEEE, 2015.

[33] K. A. Corzine, M. W. Wielebski, F. Z. Peng, and J. Wang, "Control of cascaded multilevel inverters," IEEE Transactions on Power Electronics, vol. 19, no. 3, pp. 732-738, 2004.

[34] J. Pereda and J. Dixon, "Cascaded multilevel converters: Optimal asymmetries and floating capacitor control," IEEE Transactions on Industrial Electronics, vol. 60, no. 11, pp. 4784-4793, 2013.

[35] S. Lu, S. Mariéthoz, and K. A. Corzine, "Asymmetrical cascade multilevel converters with noninteger or dynamically changing dc voltage ratios: Concepts and modulation techniques," IEEE Transactions on Industrial Electronics, vol. 57, no. 7, pp. 2411-2418, 2010.

[36] M. G. Majumder, A. K. Yadav, K. Gopakumar, U. Loganathan, L. G. Franquelo et al., "A 5-level inverter scheme using single dc link with reduced number of floating capacitors and switches for open-end im drives," IEEE Transactions on Industrial Electronics, vol. 67, no. 2, pp. 960-968, 2019.

[37] M. G. Majumder, R. Rakesh, K. Gopakumar, L. Umanand, K. AlHaddad, and W. Jarzyna, "A fault-tolerant five-level inverter topology with reduced component count for oeim drives," IEEE Journal of Emerging and Selected Topics in Power Electronics, vol. 9, no. 1, pp. 961-969, 2020.

[38] Y. Oto, T. Noguchi, T. Sasaya, T. Yamada, and R. Kazaoka, "Space vector modulation of dual inverter system focusing on improvement of multilevel voltage waveforms," IEEE Transactions on Industrial Electronics, vol. 66, no. 12, pp. 9139-9148, 2019.

[39] Z. Huang, T. Yang, P. Giangrande, M. Galea, C. Garcia, M. Rivera, P. Wheeler, and J. Rodriguez, "Voltage utilization enhancement of dual inverters by model predictive control for motor drive applications," in 2019 IEEE International Symposium on Predictive Control of Electrical Drives and Power Electronics (PRECEDE), DOI 10.1109/PRECEDE.2019.8753341, pp. 1-3, 2019.

[40] Y. Lee and J.-I. Ha, "Hybrid modulation of dual inverter for open-end permanent magnet synchronous motor," IEEE Transactions on Power Electronics, vol. 30, no. 6, pp. 3286-3299, 2015.

[41] D. Pan, F. Liang, Y. Wang, and T. A. Lipo, "Extension of the operating region of an IPM motor utilizing series compensation," IEEE Transactions on Industry Applications, vol. 50, no. 1, pp. 539-548, 2013.

[42] M. Mengoni, A. Amerise, L. Zarri, A. Tani, G. Serra, and D. Casadei, "Control scheme for open-ended induction motor drives with a floating capacitor bridge over a wide speed range," IEEE Transactions on Industry Applications, vol. 53, no. 5, pp. 4504-4514, 2017.

[43] Z. Huang, T. Yang, P. Giangrande, P. Wheeler, and M. Galea, "An active modulation scheme for avoiding overcharging in the dual converter with isolated asymmetric supplies," in 21st European Conference on Power Electronics and Applications (EPE), pp. 1-9. IEEE, 2019.

[44] B. V. Reddy, V. T. Somasekhar, and Y. Kalyan, "Decoupled spacevector PWM strategies for a four-level asymmetrical open-end winding induction motor drive with waveform symmetries," IEEE Transactions on Industrial Electronics, vol. 58, no. 11, pp. 5130-5141, 2011.

[45] M. Baiju, K. Mohapatra, R. Kanchan, and K. Gopakumar, "A dual two-level inverter scheme with common mode voltage elimination for an induction motor drive," IEEE Transactions on Power Electronics, vol. 19, no. 3, pp. 794-805, 2004.

[46] Y. Zhou and H. Nian, "Zero-sequence current suppression strategy of open-winding PMSG system with common DC bus based on zero 
vector redistribution," IEEE Transactions on Industrial Electronics, vol. 62, no. 6, pp. 3399-3408, 2015.

[47] L. Rovere, A. Formentini, G. L. Calzo, P. Zanchetta, and T. Cox, "Zerosequence voltage elimination for dual fed common DC-link open-end winding PMSM high speed starter-generator, part i: Modulation,' IEEE Transactions on Industry Applications, vol. 55, no. 6, pp. 7804-7812, 2019.

[48] L. Rovere, A. Formentini, G. L. Calzo, P. Zanchetta, and T. Cox, "Zerosequence voltage elimination for dual fed common DC-link openend winding PMSM high speed starter-generator, part ii: Dead time hysteresis control of zero-sequence current," IEEE Transactions on Industry Applications, vol. 55, no. 6, pp. 7813-7821, 2019.

[49] S. Chowdhury, P. W. Wheeler, C. Gerada, and C. Patel, "Model predictive control for a dual-active bridge inverter with a floating bridge," IEEE Transactions on Industrial Electronics, vol. 63, no. 9, pp. $5558-5568,2016$.

[50] M. Priestley, J. E. Fletcher, and C. Tan, "Space-vector PWM technique for five-phase open-end winding PMSM drive operating in the overmodulation region," IEEE Transactions on Industrial Electronics, vol. 65 , no. 9 , pp. 6816-6827, 2018.

[51] J. Kalaiselvi and S. Srinivas, "Bearing currents and shaft voltage reduction in dual-inverter-fed open-end winding induction motor with reduced CMV PWM methods," IEEE Transactions on Industrial Electronics, vol. 62, no. 1, pp. 144-152, 2015.

[52] R. Baranwal, K. Basu, and N. Mohan, "Carrier-based implementation of SVPWM for dual two-level vsi and dual matrix converter with zero common-mode voltage," IEEE Transactions on Power Electronics, vol. 30, no. 3, pp. 1471-1487, 2015.

[53] J. Riedemann, J. C. Clare, P. W. Wheeler, R. Blasco-Gimenez, M. Rivera, and R. Pena, "Open-end winding induction machine fed by a dual-output indirect matrix converter," IEEE Transactions on Industrial Electronics, vol. 63, no. 7, pp. 4118-4128, 2016.

[54] E. Shivakumar, K. Gopakumar, S. Sinha, A. Pittet, and V. Ranganathan, "Space vector PWM control of dual inverter fed open-end winding induction motor drive," EPE Journal, vol. 12, no. 1, pp. 9-18, 2002.

[55] S. Srinivas and V. Somasekhar, "Space-vector-based PWM switching strategies for a three-level dual-inverter-fed open-end winding induction motor drive and their comparative evaluation," IET Electric Power Applications, vol. 2, no. 1, pp. 19-31, 2008.

[56] D. Casadei, G. Grandi, A. Lega, and C. Rossi, "Multilevel operation and input power balancing for a dual two-level inverter with insulated DC sources," IEEE Transactions on Industry Applications, vol. 44, no. 6, pp. 1815-1824, 2008.

[57] S. Srinivas and K. R. Sekhar, "Theoretical and experimental analysis for current in a dual-inverter-fed open-end winding induction motor drive with reduced switching PWM," IEEE Transactions on Industrial Electronics, vol. 60, no. 10, pp. 4318-4328, 2013.

[58] P. Srinivasan, B. L. Narasimharaju, and N. V. Srikanth, "Space-vector pulse width modulation scheme for open-end winding induction motor drive configuration," IET Power Electronics, vol. 8, no. 7, pp. 10831094, 2015.

[59] S. Lakhimsetty and V. T. Somasekhar, "A four-level open-end winding induction motor drive with a nested rectifier-inverter combination with two DC power supplies," IEEE Transactions on Power Electronics, vol. 34, no. 9, pp. 8894-8904, 2019.

[60] K. Corzine, S. Sudhoff, and C. Whitcomb, "Performance characteristics of a cascaded two-level converter," IEEE Transactions on Energy Conversion, vol. 14, no. 3, pp. 433-439, 1999.

[61] E. Shivakumar, V. Somasekhar, K. K. Mohapatra, K. Gopakumar, L. Umanand, and S. Sinha, "A multi level space phasor based PWM strategy for an open-end winding induction motor drive using two inverters with different DC link voltages," in Power Electronics and Drive Systems, 2001. Proceedings., 2001 4th IEEE International Conference on, vol. 1, pp. 169-175. IEEE, 2001.

[62] V. Somasekhar, E. Shivakumar, K. Gopakumar, and A. Pittet, "Multi level voltage space phasor generation for an open-end winding induction motor drive using a dual inverter scheme with asymmetrical DClink voltages," EPE Journal, vol. 12, no. 3, pp. 59-77, 2002.

[63] B. V. Reddy and V. T. Somasekhar, "A dual inverter fed four-level openend winding induction motor drive with a nested rectifier-inverter," IEEE Transactions on Industrial Informatics, vol. 9, no. 2, pp. 938946, 2013.

[64] M. Darijevic, M. Jones, and E. Levi, "An open-end winding four-level five-phase drive," IEEE Transactions on Industrial Electronics, vol. 63, no. 1 , pp. 538-549, 2016.

[65] M. Darijevic, N. Bodo, and M. Jones, "On the five-phase openend winding drives performance," in Proceedings of PCIM Europe
2015; International Exhibition and Conference for Power Electronics, Intelligent Motion, Renewable Energy and Energy Management, pp. 1-8. VDE, 2015

[66] S. Lakhimsetty, N. Surulivel, and V. Somasekhar, "Improvised SVPWM strategies for an enhanced performance for a four-level openend winding induction motor drive," IEEE Transactions on Industrial Electronics, vol. 64, no. 4, pp. 2750-2759, 2017.

[67] B. V. Reddy and V. Somasekhar, "An SVPWM scheme for the suppression of zero-sequence current in a four-level open-end winding induction motor drive with nested rectifier-inverter," IEEE Transactions on Industrial Electronics, vol. 63, no. 5, pp. 2803-2812, 2016.

[68] M. H. V. Reddy, T. B. Reddy, B. R. Reddy, and M. S. Kalavathi, "Discontinuous PWM technique for the asymmetrical dual inverter configuration to eliminate the overcharging of DC-link capacitor," IEEE Transactions on Industrial Electronics, vol. 65, no. 1, pp. 156-166, 2018.

[69] K. R. Sekhar and S. Srinivas, "Discontinuous decoupled pwms for reduced current ripple in a dual two-level inverter fed open-end winding induction motor drive," IEEE Transactions on Power Electronics, vol. 28, no. 5, pp. 2493-2502, 2013.

[70] A. D. Kiadehi, K. E. K. Drissi, and C. Pasquier, "Voltage THD reduction for dual-inverter fed open-end load with isolated DC sources," IEEE Transactions on Industrial Electronics, vol. 64, no. 3, pp. 21022111, 2017.

[71] M. Jones, M. Darijevic, and E. Levi, "Decoupled modulation techniques for a four-level five-phase open-end winding drive," in 2014 IEEE Energy Conversion Congress and Exposition (ECCE), pp. 178186. IEEE, 2014

[72] V. T. Somasekhar, B. V. Reddy, and K. Sivakumar, "A four-level inversion scheme for a $6 n$-pole open-end winding induction motor drive for an improved DC-link utilization," IEEE Transactions on Industrial Electronics, vol. 61, no. 9, pp. 4565-4572, 2014.

[73] M. Darijevic, M. Jones, O. Dordevic, and E. Levi, "Decoupled PWM control of a dual-inverter four-level five-phase drive," IEEE Transactions on Power Electronics, vol. 32, no. 5, pp. 3719-3730, 2017.

[74] M. Chen and D. Sun, "A coordinated SVPWM without sector identification for dual inverter fed open winding IPMSM system," in Energy Conversion Congress and Exposition (ECCE), 2016 IEEE, pp. 1-8. IEEE, 2016.

[75] M. Chen and D. Sun, "A unified space vector pulse width modulation for dual two-level inverter system," IEEE Transactions on Power Electronics, vol. 32, no. 2, pp. 889-893, 2017.

[76] V. Somasekhar, K. Gopakumar, and M. Baiju, "Dual two-level inverter scheme for an open-end winding induction motor drive with a single DC power supply and improved DC bus utilisation," IEE ProceedingsElectric Power Applications, vol. 151, no. 2, pp. 230-238, 2004.

[77] H. Zhan, Z. Zhu, M. Odavic, and Y. Li, "A novel zero-sequence modelbased sensorless method for open-winding PMSM with common DC bus," IEEE Transactions on Industrial Electronics, vol. 63, no. 11, pp. 6777-6789, 2016.

[78] W. Hu, H. Nian, and D. Sun, "Zero-sequence current suppression strategy with reduced switching frequency for open-end winding PMSM drives with common DC bus," IEEE Transactions on Industrial Electronics, vol. 66, no. 10, pp. 7613-7623, 2018.

[79] V. Somasekhar, S. Srinivas, B. P. Reddy, C. N. Reddy, and K. Sivakumar, "Pulse width-modulated switching strategy for the dynamic balancing of zero-sequence current for a dual-inverter fed open-end winding induction motor drive," IET Electric Power Applications, vol. 1, no. 4, pp. 591-600, 2007.

[80] V. T. Somasekhar, S. Srinivas, and K. K. Kumar, "Effect of zero-vector placement in a dual-inverter fed open-end winding induction motor drive with alternate sub-hexagonal center PWM switching scheme," IEEE Transactions on Power Electronics, vol. 23, no. 3, pp. 15841591, 2008.

[81] S. Srinivas and J. Kalaiselvi, "Pulse width modulation schemes enabling single DC power source driven dual two-level voltage source inverter with single voltage source inverter switching," IET Power Electronics, vol. 7, no. 5, pp. 1181-1191, 2014.

[82] V. T. Somasekhar, S. Srinivas, and K. K. Kumar, "Effect of zero-vector placement in a dual-inverter fed open-end winding induction-motor drive with a decoupled space-vector PWM strategy," IEEE Transactions on Industrial Electronics, vol. 55, no. 6, pp. 2497-2505, 2008.

[83] A. D. kiadehi, K. E. K. Drissi, C. Pasquier et al., "Angular modulation of dual-inverter fed open-end motor for electrical vehicle applications," IEEE Transactions on Power Electronics, vol. 31, no. 4, pp. 2980-2990, 2016. 
[84] S. G. Jayasinghe, D. M. Vilathgamuwa, and U. K. Madawala, "A dual inverter-based supercapacitor direct integration scheme for wind energy conversion systems," IEEE Transactions on Industry Applications, vol. 49, no. 3, pp. 1023-1030, 2013.

[85] S. Jayasinghe, D. M. Vilathgamuwa, and U. K. Madawala, "A novel DC-link voltage regulation method for single source hybrid multilevel inverters," in Power Electronics Conference (IPEC), 2010 International, pp. 740-745. IEEE, 2010.

[86] S. Lu and K. A. Corzine, "Advanced control and analysis of cascaded multilevel converters based on pq compensation," IEEE Transactions on Power Electronics, vol. 22, no. 4, pp. 1242-1252, 2007.

[87] D. Sun, Z. Zheng, B. Lin, W. Zhou, and M. Chen, "A hybrid PWM-based field weakening strategy for a hybrid-inverter-driven openwinding PMSM system," IEEE Transactions on Energy Conversion, vol. 32 , no. 3 , pp. $857-865,2017$.

[88] I. J. Smith and J. Salmon, "High-efficiency operation of an open-ended winding induction motor using constant power factor control," IEEE Transactions on Power Electronics, vol. 33, no. 12, pp. 10663-10672, 2018.

[89] S. Foti, A. Testa, G. Scelba, S. De Caro, M. Cacciato, G. Scarcella, and T. Scimone, "An open-end winding motor approach to mitigate the phase voltage distortion on multilevel inverters," IEEE Transactions on Power Electronics, vol. 33, no. 3, pp. 2404-2416, 2018.

[90] A. Amerise, M. Mengoni, L. Zarri, A. Tani, S. Rubino, and R. Bojoi, "Open-end windings induction motor drive with floating capacitor bridge at variable dc-link voltage," IEEE Transactions on Industry Applications, vol. 55, no. 3, pp. 2741-2749, 2019.

[91] M. Darijević, "Modulation and control strategies for multilevel fivephase open-end winding drives," Ph.D. dissertation, Liverpool John Moores University, 2016.

[92] H. Stemmler and P. Guggenbach, "Configurations of high-power voltage source inverter drives," in Power Electronics and Applications, 1993., Fifth European Conference on, pp. 7-14. IET, 1993.

[93] Y. Oto and T. Noguchi, "Fault-tolerant function of dc-bus power source in a dual inverter drive system and its operation characteristics," IEEJ Journal of Industry Applications, vol. 8, no. 6, pp. 953-959, 2019.

[94] C. Perera, G. J. Kish, and J. Salmon, "Decoupled floating capacitor voltage control of a dual inverter drive for an open-ended winding induction motor," IEEE Transactions on Power Electronics, vol. 35, no. 7, pp. 7305-7316, 2020.

[95] Z. Huang, T. Yang, P. Giangrande, P. Wheeler, and M. Galea, "An enhanced unified space vector modulation technique for dual converters with isolated voltage supplies," in 45th Annual Conference of the IEEE Industrial Electronics Society (IECON), pp. 1-6. IEEE, 2019.

[96] A. Lega, "Multilevel converters: dual two-level inverter scheme," Ph.D. dissertation, University of Bologna, 2007.

[97] Y. Zuo, X. Zhu, X. Si, and C. H. Lee, "Fault-tolerant control for multiple open-leg faults in open-end winding permanent magnet synchronous motor system based on winding reconnection," IEEE Transactions on Power Electronics, vol. 36, no. 5, pp. 6068-6078, 2020.

[98] B. Zhu, C. Tan, M. Farshadnia, and J. E. Fletcher, "Postfault zerosequence current injection for open-circuit diode/switch failure in open-end winding pmsm machines," IEEE Transactions on Industrial Electronics, vol. 66, no. 7, pp. 5124-5132, 2018.

[99] B. Zhu, D. Xiao, C. Tan, and J. Fletcher, "Fault tolerant online condition monitor of dc-link capacitor for open-end winding machine," in IECON 2019-45th Annual Conference of the IEEE Industrial Electronics Society, vol. 1, pp. 4623-4629. IEEE, 2019.

[100] Z. Song, F. Zhou, Y. Yu, R. Zhang, and S. Hu, "Open-phase faulttolerant predictive control strategy for open-end-winding permanent magnet synchronous machines without postfault controller reconfiguration," IEEE Transactions on Industrial Electronics, vol. 68, no. 5, pp. 3770-3781, 2020.

[101] J. Kim, J. Jung, and K. Nam, "Dual-inverter control strategy for high-speed operation of EV induction motors," IEEE Transactions on Industrial Electronics, vol. 51, no. 2, pp. 312-320, 2004.

[102] P. H. Kumar, S. Lakhimsetty, and V. Somasekhar, "An open-end winding bldc motor drive with fault diagnosis and autoreconfiguration," IEEE Journal of Emerging and Selected Topics in Power Electronics, vol. 8, no. 4, pp. 3723-3735, 2019.

[103] P. Lezana, J. Pou, T. A. Meynard, J. Rodriguez, S. Ceballos, and F. Richardeau, "Survey on fault operation on multilevel inverters," IEEE Transactions on Industrial Electronics, vol. 57, no. 7, pp. 2207-2218, 2009.

[104] G. Watthewaduge, M. S. Toulabi, S. Filizadeh, and A. M. Gole, "Performance analysis and operating limits of a dual-inverter open- winding ipmsm drive," IEEE Transactions on Energy Conversion, vol. 34, no. 3, pp. 1655-1666, 2019.

[105] L. Rovere, G. Valente, A. Formentini, and P. Zanchetta, "Parameters and volt-ampere ratings of a floating capacitor open-end winding synchronous motor drive for extended cpsr," IEEE Transactions on Industrial Electronics, DOI 10.1109/TIE.2021.3076917, pp. 1-1, 2021.

[106] D. Minaglia, L. Rovere, A. Formentini, R. Leuzzi, S. Pipolo, M. Marchesoni, and P. Zanchetta, "Control of a dual fed open end winding spmsm with a floating capacitor," in 2020 IEEE Energy Conversion Congress and Exposition (ECCE), pp. 4036-4043. IEEE, 2020.

[107] J. K. Nøland, M. Leandro, J. A. Suul, and M. Molinas, "High-power machines and starter-generator topologies for more electric aircraft: A technology outlook," IEEE Access, vol. 8, pp. 130 104-130 123, 2020.

[108] J. Ou, Y. Liu, D. Liang, and M. Doppelbauer, "Investigation of pm eddy current losses in surface-mounted pm motors caused by pwm," IEEE Transactions on Power Electronics, vol. 34, no. 11, pp. 11 253-11263, 2019.

[109] P. Wheeler and S. Bozhko, "The more electric aircraft: Technology and challenges." IEEE Electrification Magazine, vol. 2, no. 4, pp. 612,2014

[110] G. L. Calzo, "Power generating unit for the future more electric aircraft: power electronic converter modelling and design," Ph.D. dissertation, Università degli studi Roma Tre, 2015.

[111] B. Sarlioglu and C. T. Morris, "More electric aircraft: Review, challenges, and opportunities for commercial transport aircraft," IEEE transactions on Transportation Electrification, vol. 1, no. 1, pp. 54-64, 2015.

[112] J. Wei, Q. Deng, B. Zhou, M. Shi, and Y. Liu, "The control strategy of open-winding permanent magnet starter-generator with inverterrectifier topology," IEEE Transactions on Industrial Informatics, vol. 9 , no. 2, pp. 983-991, 2012.

[113] J. Reimers, L. Dorn-Gomba, C. Mak, and A. Emadi, "Automotive traction inverters: Current status and future trends," IEEE Transactions on Vehicular Technology, vol. 68, no. 4, pp. 3337-3350, 2019.

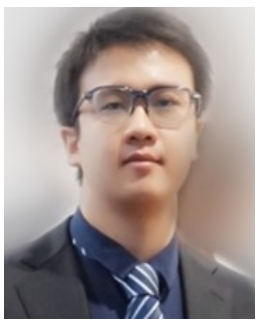

Zhen Huang received the B.Eng. (hons.) degree in electrical and electronics engineering in 2015, and the Ph.D. in electrical engineering in 2019, both from the University of Nottingham, Nottingham, UK.

Since January 2020, he has been a Research Fellow with the Power Electronics, Machines and Control Group, the University of Nottingham. His research interests include high-speed machine drives, multilevel converters, and on-board electrical power system protection for hybrid/all-electric vehicles and more/all-electric aircraft applications.

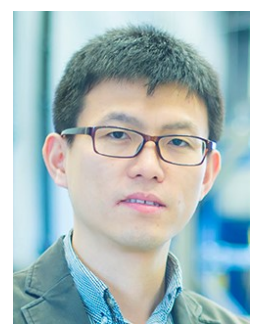

Tao Yang (Senior Member, IEEE) received the M.Eng Degree from Shanghai Jiao Tong University, China in 2008 and the Ph.D. degree in electrical engineering from the University of Nottingham, UK in 2013. His $\mathrm{PhD}$ research within EU Clean Sky on 'Modelling electrical power system for more-electric aircraft applications' has resulted in him winning the inaugural Clean Sky Best $\mathrm{PhD}$ Award in 2016

Since 2013, he has been a Researcher with Power Electronics, Machines and Control Group, University of Nottingham, where he became an Assistant Professor in 2016, and an Associate Professor in 2019. His research interests include high-speed electric motor drive control, power electronic conversion, electrical system design and optimization for more electric/hybrid/all-electric aircraft applications.

Dr. Yang is an Associate Editor for the IEEE TRANSACTIONS ON TRANSPORTATION ELECTRIFICATION and Chinese Journal of Aeronautics. 


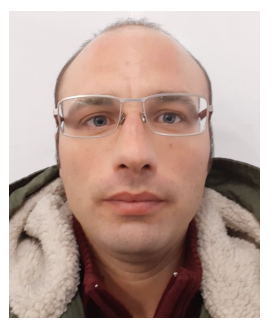

Paolo Giangrande (Senior Member, IEEE) received the bachelor's (hons.), master's (hons.), and $\mathrm{Ph} . \mathrm{D}$. degrees in electrical engineering from the Politecnico of Bari, Bari, Italy, in 2005, 2008, and 2011, respectively.

Since 2012, he has been a Research Fellow with the Power Electronics, Machines, and Control Group at the University of Nottingham, U.K. In 2018, he was appointed as a Senior Research Fellow and he is currently the Head of the Accelerated Lifetime Testing Laboratory at the Institute of Aerospace Technology, Nottingham. His main research interests include sensorless control of ac electric drives, design and testing of electromechanical actuators for aerospace, thermal management of high-performance electric drives, and lifetime modeling of electrical machines.

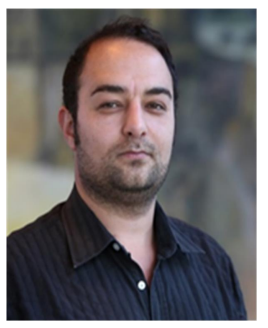

Michael Galea (Senior Member, IEEE) received the Ph.D. degree in electrical machines design from the University of Nottingham, Nottingham, U.K., in 2013.

He was appointed as Lecturer, as Associate Professor, and as Professor in electrical machines and drives with the University of Nottingham, in 2014, 2018, and 2019, respectively. He currently lectures in electrical machines and drives and in aerospace systems integration and manages a number of diverse projects and programmes related to the more/all electric aircraft, electrified propulsion, and associated fields His main research interests include design and development of electrical machines and drives (classical and unconventional), reliability and lifetime degradation of electrical machines and the more electric aircraft.

Dr. Michael is a fellow of the Royal Aeronautical Society. He also serves an Associate Editor for the IEEE TRANSACTIONS ON INDUSTRIAL ELECTRONICS and for the IET ELECTRICAL SYSTEMS IN TRANSPORTATION.

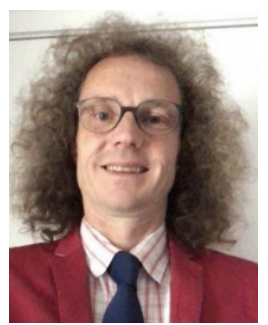

Pat Wheeler (Fellow, IEEE) received his B.Eng. (hons.) in electrical engineering in 1990 and his $\mathrm{Ph} . \mathrm{D}$. degree for his work on matrix converters in 1994, both from the University of Bristol, Bristol, U.K.

In 1993, he moved to the University of Nottingham, Nottingham, U.K., and worked as a Research Assistant with the Department of Electrical and Electronic Engineering. In 1996, he became a Lecturer with the Power Electronics, Machines and Control Group, University of Nottingham, where he has been a Full Professor since January 2008. From 2015 to 2018, he was the Head of the Department of Electrical and Electronic Engineering, University of Nottingham. He has authored/co-authored over 700 academic publications in leading international conferences and journals.

Prof. Wheeler is currently the Head of the Power Electronics, Machines and Control Research Group, Global Director of the University of Nottingham's Institute of Aerospace Technology and was the Li Dak Sum Chair Professor in Electrical and Aerospace Engineering (2016 to 2020). He is a member of the IEEE PELS AdCom and was an IEEE PELS Distinguished Lecturer from 2013 to 2017. 